\title{
Carbon Nanotubes in Biology and Medicine: In vitro and in vivo Detection, Imaging and Drug Delivery
}

\author{
Zhuang Liu, Scott Tabakman, Kevin Welsher, and Hongjie Dai $(\bowtie)$ \\ Department of Chemistry, Stanford University, CA 94305, USA \\ Received: 23 October 2008 / Revised: 1 December 2008 / Accepted: 2 December 2008 \\ (CTsinghua University Press and Springer-Verlag 2009. This article is published with open access at Springerlink.com
}

\begin{abstract}
Carbon nanotubes exhibit many unique intrinsic physical and chemical properties and have been intensively explored for biological and biomedical applications in the past few years. In this comprehensive review, we summarize the main results from our and other groups in this field and clarify that surface functionalization is critical to the behavior of carbon nanotubes in biological systems. Ultrasensitive detection of biological species with carbon nanotubes can be realized after surface passivation to inhibit the non-specific binding of biomolecules on the hydrophobic nanotube surface. Electrical nanosensors based on nanotubes provide a label-free approach to biological detection. Surface-enhanced Raman spectroscopy of carbon nanotubes opens up a method of protein microarray with detection sensitivity down to $1 \mathrm{fmol} / \mathrm{L}$. In vitro and in vivo toxicity studies reveal that highly water soluble and serum stable nanotubes are biocompatible, nontoxic, and potentially useful for biomedical applications. In vivo biodistributions vary with the functionalization and possibly also size of nanotubes, with a tendency to accumulate in the reticuloendothelial system (RES), including the liver and spleen, after intravenous administration. If well functionalized, nanotubes may be excreted mainly through the biliary pathway in feces. Carbon nanotube-based drug delivery has shown promise in various In vitro and in vivo experiments including delivery of small interfering RNA (siRNA), paclitaxel and doxorubicin. Moreover, single-walled carbon nanotubes with various interesting intrinsic optical properties have been used as novel photoluminescence, Raman, and photoacoustic contrast agents for imaging of cells and animals. Further multidisciplinary explorations in this field may bring new opportunities in the realm of biomedicine.
\end{abstract}

\section{KEYWORDS}

Carbon nanotubes, biomedical applications, surface functionalization, biosensor, drug delivery, biomedical imaging

\section{Introduction}

Nanomaterials have sizes ranging from about one nanometer up to several hundred nanometers, comparable to many biological macromolecules such as enzymes, antibodies, and DNA plasmids. Materials in this size range exhibit interesting physical properties, distinct from both the molecular and bulk scales, presenting new opportunities for biomedical research and applications in various

Address correspondence to hdai@stanford.edu 
areas including biology and medicine. The emerging field of nanobiotechnology bridges the physical sciences with biological sciences via chemical methods in developing novel tools and platforms for understanding biological systems and disease diagnosis and treatment [1-3].

Carbon nanotubes (CNTs) are rolled up seamless cylinders of graphene sheets, exhibiting unparalleled physical, mechanical, and chemical properties which have attracted tremendous interest in the past decade [4-8]. Depending on the number of graphene layers from which a single nanotube is composed, CNTs are classified as single-walled carbon nanotubes (SWNTs) or multi-walled carbon nanotubes (MWNTs). Applications of CNTs span many fields and applications, including composite materials [9], nanoelectronics [10,11], field-effect emitters [12], and hydrogen storage [13]. In recent years, efforts have also been devoted to exploring the potential biological applications of CNTs, motivated by their interesting size, shape, and structure, as well as attractive and unique physical properties [14-17].

With diameters of 1-2 $\mathrm{nm}$, and lengths ranging from as short as $50 \mathrm{~nm}$ up to $1 \mathrm{~cm}$, SWNTs are one-dimensional (1-D) nanomaterials which may behave distinctly from spherical nanoparticles in biological environments, offering new opportunities in biomedical research. The flexible 1-D nanotube may bend to facilitate multiple binding sites of a functionalized nanotube to one cell, leading to a multi-valence effect, and improved binding affinity of nanotubes conjugated with targeting ligands. With all atoms exposed on the surface, SWNTs have ultrahigh surface area (theoretically $1300 \mathrm{~m}^{2} / \mathrm{g}$ ) that permits efficient loading of multiple molecules along the length of the nanotube sidewall. Moreover, supramolecular binding of aromatic molecules can be easily achieved by $\pi-\pi$ stacking of those molecules onto the polyaromatic surface of nanotubes [18].

SWNTs are quasi 1-D quantum wires with sharp densities of electronic states (electronic DOS) at the van Hove singularities (Fig. 1(a)), which impart distinctive optical properties to SWNTs [19]. SWNTs are highly absorbing materials with strong optical absorption in the near-infrared (NIR) range due to E11 optical transitions (Figs. 1(a) and 1(b)), and thus can be utilized for photothermal therapy [20,21] and photoacoustic imaging [22]. Semiconducting SWNTs with small band gaps on the order of $1 \mathrm{eV}$ exhibit photoluminescence in the NIR range. The emission range of SWNTs is $800-2000 \mathrm{~nm}[17,23,24]$, which covers the biological tissue transparency window, and is therefore suitable for biological imaging. SWNTs also have distinctive resonance-enhanced Raman signatures for Raman detection/imaging, with large scattering cross-sections for single tubes $[25,26]$. The intrinsic physical properties of SWNTs can be utilized for multimodality imaging and therapy.

In contrast to SWNTs, MWNTs are formed by multiple layers of graphene and have much larger diameters (10-100 nm). Although MWNTs exhibit less rich and attractive optical properties than SWNTs, their use in biological systems could be different from that of SWNTs due to their larger sizes, which could offer different platforms for different purposes, such as delivery of large biomolecules including DNA plasmids into cells [27-30].

Motivated by various properties of CNTs, research towards applying carbon nanotubes for biomedical applications has been progressing rapidly. CNT-based sensors have been developed to detect biological species including proteins and DNA [14, 31, 32]. Relying on their optical properties, SWNTs can be utilized as optical tags or contrast agents for various biological imaging techniques [17, 22, 24, 26]. Our group and others have shown that properly functionalized CNTs are able to enter cells without toxicity, shuttling various biological molecular cargoes into cells $[15,16,29,33-36]$. Our latest study has shown the promise of using CNTs for in vivo cancer treatment in a mouse model [37]. However, despite these exciting findings, researchers have reported the negative sides of CNTs, showing that nonfunctionalized nanotubes are toxic to cells and animals [38-43]. The biodistribution and long-term fate of CNTs have been explored by us and several different groups, with different results obtained using different methods and materials [44-50]. These controversial findings require clarification in order to avoid confusion to the public.

In this review, we first summarize the various 


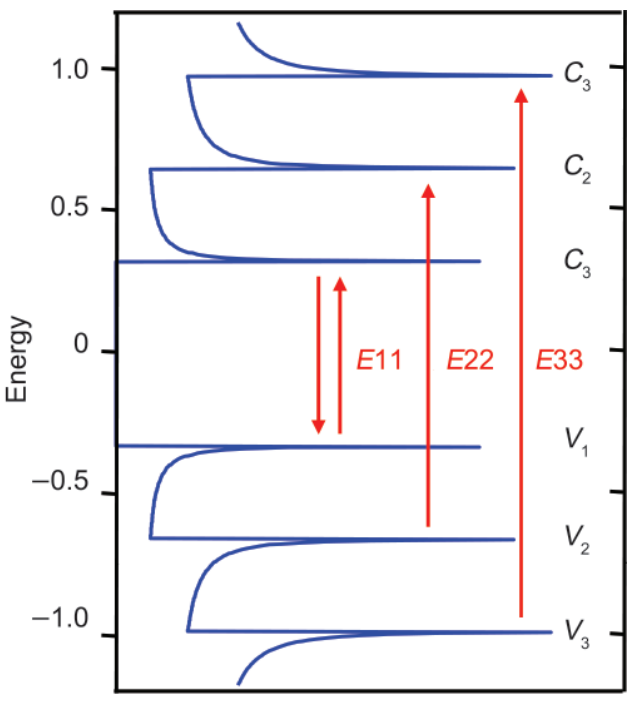

Density of electronic states

(a)

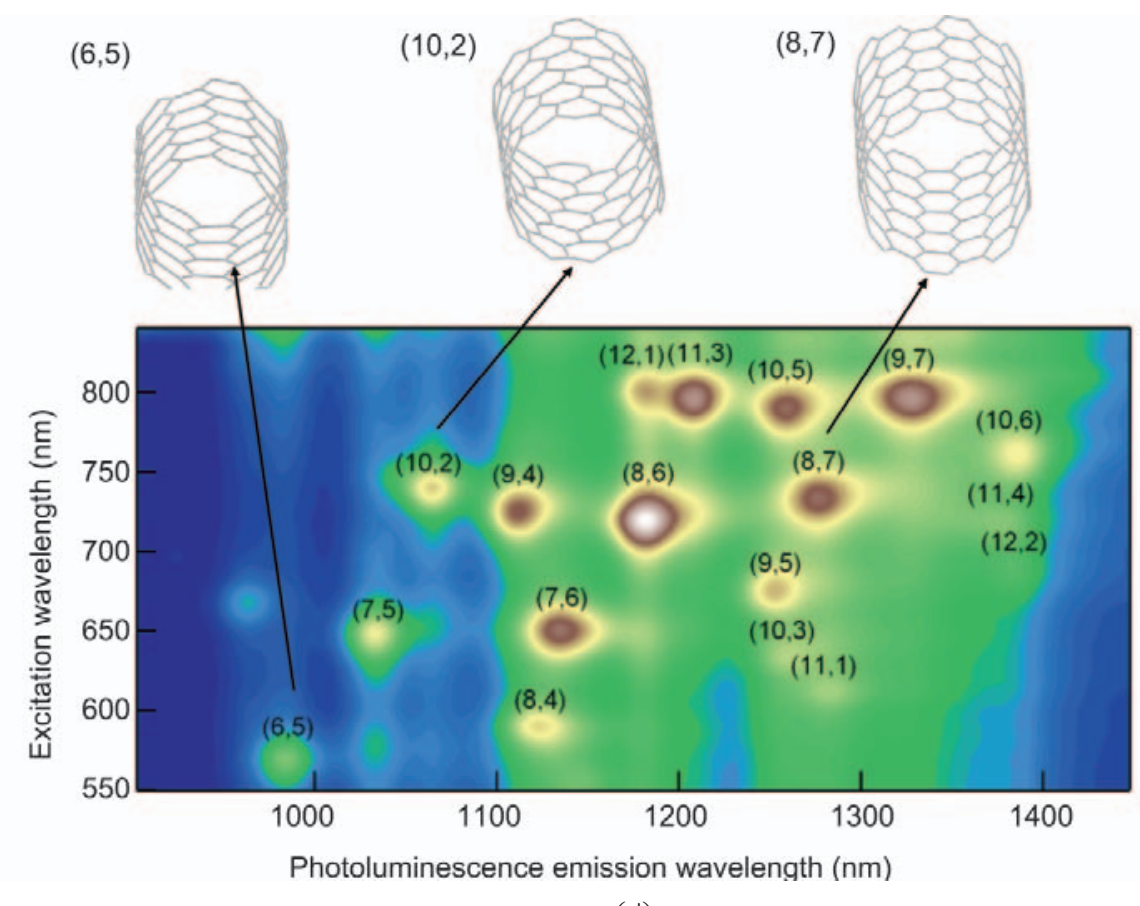

(d)
$(10,2)$

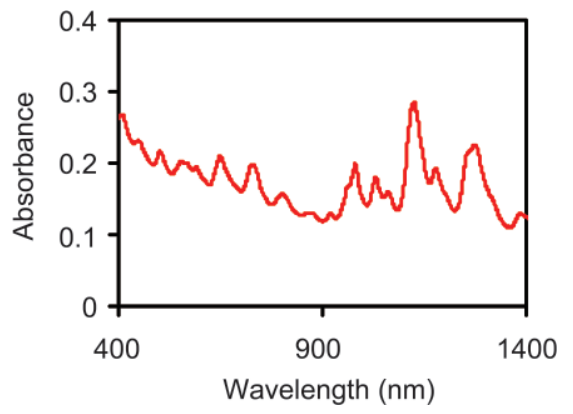

(b)

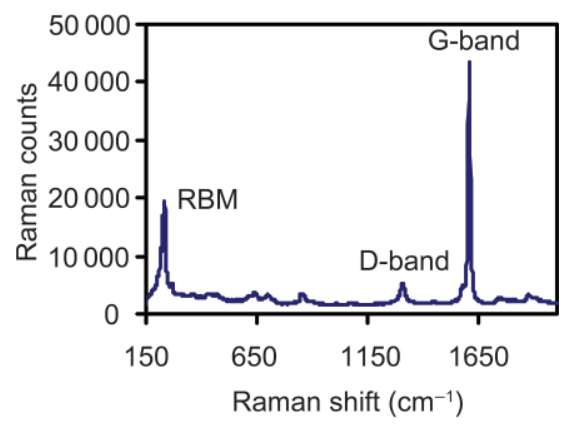

(c) 
routes used to functionalize carbon nanotubes including covalent and noncovalent methods. Carbon nanotube-based electronic and optical biosensors are then discussed. Surveying our and others results, we next describe work which has shown that while nonfunctionalized, hydrophobic CNTs have shown toxicity [38-43], those with carefully designed biocompatible coatings are harmless to cells In vitro [17, 18, 20, 51-57] and in vivo, at least to mice within tested dose ranges $[45,58]$. In terms of biodistribution, although direct comparison between different studies may not be valid because of the different CNT materials used, tracking SWNTs themselves by their intrinsic physical properties (Raman scattering, photoluminescence, ${ }^{13} \mathrm{C}$ isotope mass spectrum) shows that, similar to other nanoparticles in vivo, after systemic administration SWNTs are predominantly localized in the reticuloendothelial system (RES) including the liver and spleen $[45,48,50]$. We also review the current progress in the use of carbon nanotubes for In vitro drug delivery studies as well as pioneering efforts towards in vivo cancer treatment. Lastly, SWNTbased biomedical imaging In vitro and in vivo are discussed.

\section{Functionalization of carbon nanotubes for biological applications}

As grown, raw carbon nanotubes have highly hydrophobic surfaces, and are not soluble in aqueous solutions. For biomedical applications, surface chemistry or functionalization is required to solubilize CNTs, and to render biocompatibility and low toxicity. Surface functionalization of carbon nanotubes may be covalent or noncovalent. Chemical reactions forming bonds with nanotube sidewalls are carried out in the covalent functionalization case, while noncovalent functionalization exploits favorable interactions between the hydrophobic domain of an amphiphilic molecule and the CNT surface, affording aqueous nanotubes wrapped by surfactant.

\subsection{Covalent functionalization of carbon nanotubes}

Various covalent reactions have been developed to functionalize carbon nanotubes, oxidation being one of the most common. CNT oxidation is carried out with oxidizing agents such as nitric acid $[59,60]$. During the process, carboxyl groups are formed at the ends of tubes as well as at the defects on the sidewalls. Zeng et al. observed $\mathrm{sp}^{3}$ carbon atoms on SWNTs after oxidation and further covalent conjugation with amino acids [61]. However, although oxidized CNTs are soluble in water, they aggregate in the presence of salts due to charge screening effects, and thus cannot be directly used for biological applications due to the high salt content of most biological solutions. Further modification can be achieved by attaching hydrophilic polymers such as poly(ethylene glycol) (PEG) to oxidized CNTs, yielding CNT-polymer conjugates stable in biological environments (Fig. 2(a)) $[18,58,62]$. We have used covalently PEGylated SWNTs synthesized by this strategy for both In vitro and in vivo applications $[18,58]$.

Another widely used type of covalent reaction to functionalize CNTs is the cylcoaddition reaction, which occurs on the aromatic sidewalls, instead of nanotube ends and defects as in the oxidation case. [2+1] Cycloadditions can be conducted by photochemical reaction of CNTs with azides (Fig. $2(b))[63,64]$ or carbene generating compounds via the Bingel reaction (Fig. 2(c)) [65, 66]. A 1,3-dipolar cycloaddition reaction on CNTs developed by Prato et al. is now a commonly used reaction (Fig. 2(d)) [67, 68]. An azomethine-ylide generated by condensation of an $\alpha$-amino acid and an aldehyde is added to the graphitic surface, forming a pyrrolidine ring coupled to the CNT sidewall. Functional groups (e.g., aminoterminated PEG) introduced via a modified $\alpha$-amino acid can be used for further conjugation of biological molecules such as peptides or drugs $[36,69]$.

Despite the robustness of the covalent functionalization method, the intrinsic physical properties of CNTs such as photoluminescence and Raman scattering are often destroyed after chemical reactions due to the disrupted nanotube structure. The intensities of Raman scattering and photoluminescence of SWNTs are drastically decreased after covalent modification, reducing the potential of optical applications of these materials. 

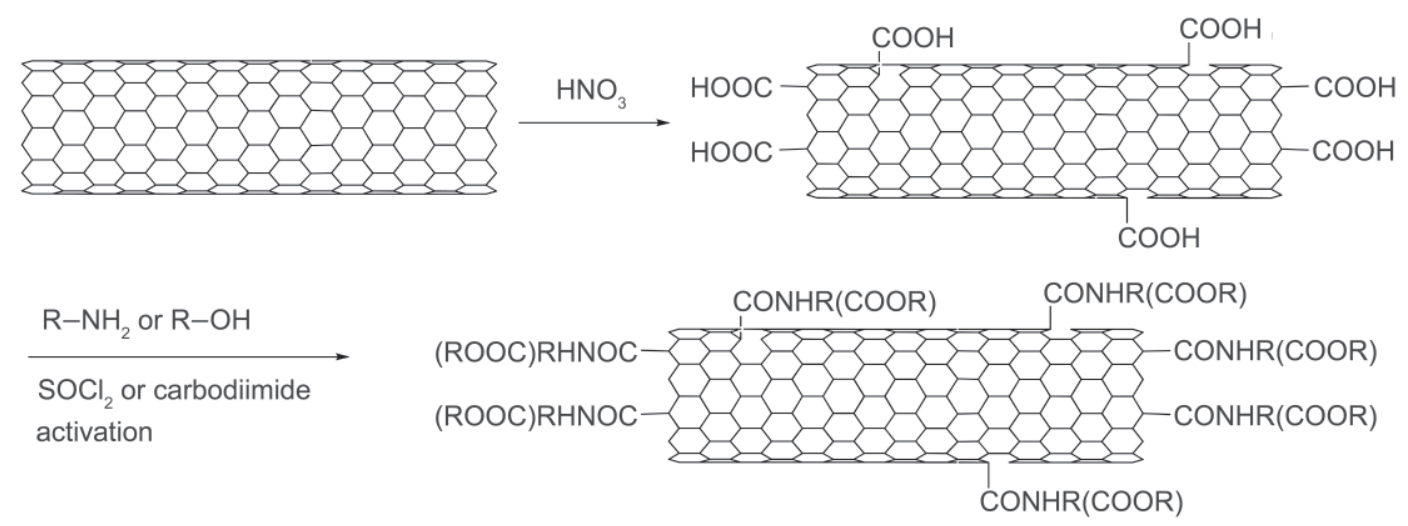

(a)
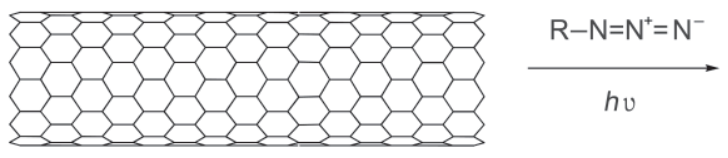

(b)
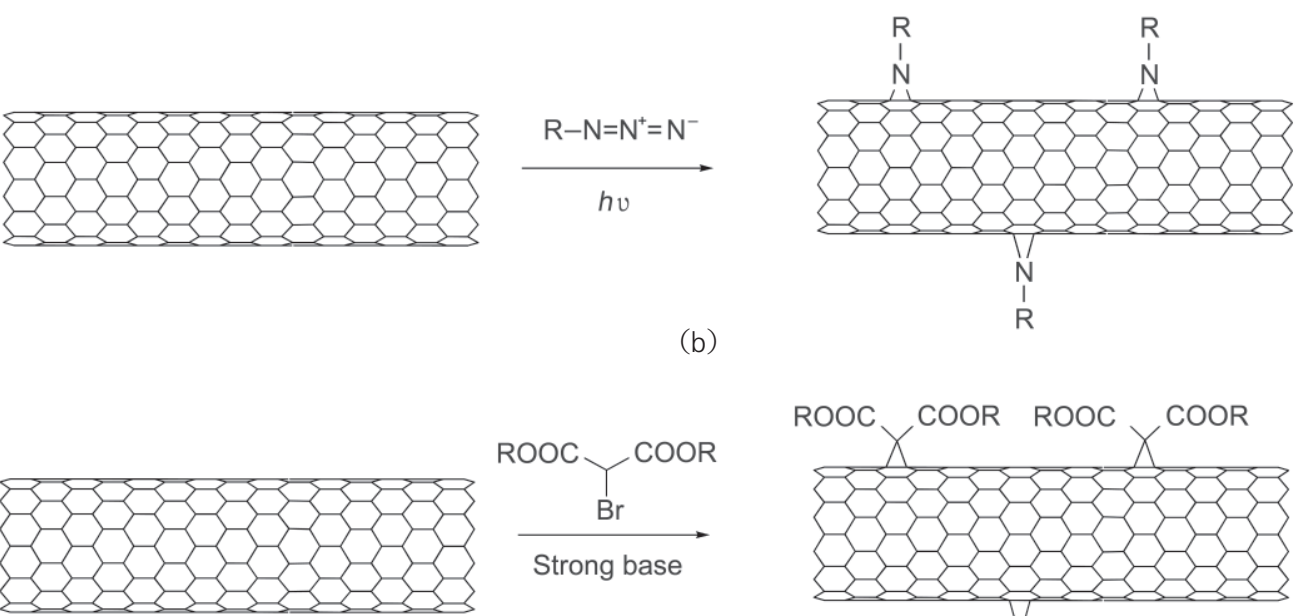

(c)
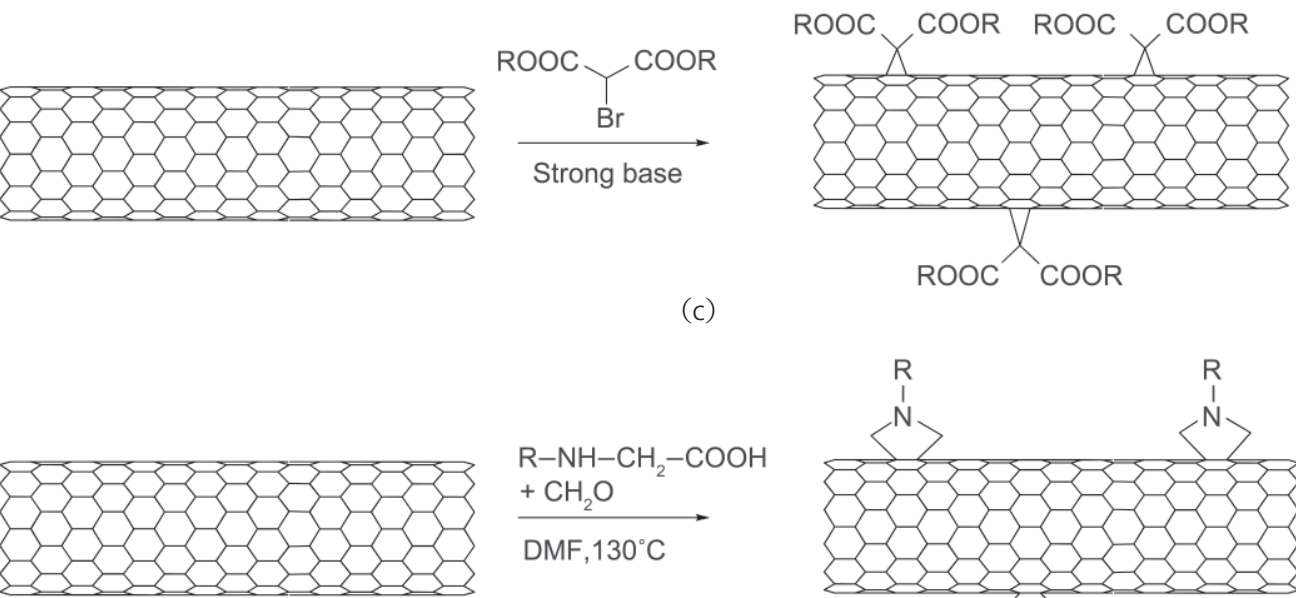

$\mathrm{R}-\mathrm{NH}-\mathrm{CH}_{2}-\mathrm{COOH}$

$+\mathrm{CH}_{2} \mathrm{O}$

$\mathrm{DMF}, 130^{\circ} \mathrm{C}$

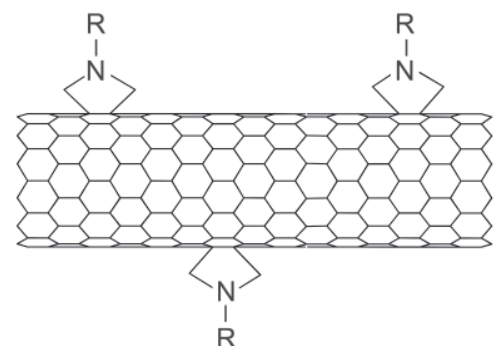

(d)

Figure 2 Schemes of covalent functionalization of carbon nanotubes: (a) CNTs are oxidized and then conjugated with hydrophilic polymers (e.g., PEG) or other functional moieties; (b) photoinduced [1, 2] addition of azide compounds with CNTs; (c) Bingel reaction on CNTs; (d) 1,3-dipolar cylcoaddition on CNTs. For biological applications, "R" in the figure is normally a hydrophilic domain which renders CNTs water soluble. Further conjugation of bioactive molecules can be applied based on such functionalizations

\subsection{Noncovalent functionalization of carbon nanotubes}

In contrast to covalent functionalization, noncovalent functionalization of CNTs can be carried out by coating CNTs with amphiphilic surfactant molecules or polymers. Since the chemical structure of the $\pi$-network of carbon nanotubes is not disrupted, except for shortening of length due to the sonication employed in the functionalization process, the physical properties of CNTs are essentially preserved by the noncovalent approach. Consequently, aqueous solutions of CNTs, especially SWNTs, engineered by noncovalent functionalization are promising for 
multiple biomedical applications including imaging.

The polyaromatic graphitic surface of a carbon nanotube is accessible to the binding of aromatic molecules via $\pi-\pi$ stacking $[70,71]$. Taking advantage of the $\pi-\pi$ interaction between pyrene and the nanotube surface, we and others have used pyrene derivatives to noncovalently functionalize carbon nanotubes (Fig. 3(a)) $[70,72]$. Chen et al. showed that proteins can be immobilized on SWNTs functionalized by an amine-reactive pyrene derivative [70]. A recent study conducted by $\mathrm{Wu}$ et al. also used pyrene conjugated glycodendrimers to solublize carbon nanotubes [72]. Beside pyrene derivatives, single-stranded DNA molecules have been widely used to solubilize SWNTs by virtue of the $\pi-\pi$ stacking between aromatic DNA base units and the nanotube surface (Fig. $3(b))[20,73,74]$. However, a recent report by Moon et al. showed that DNA molecules coated on SWNTs could be cleaved by nucleases in the serum, suggesting that DNA functionalization of SWNTs might not be stable in biological environments containing nucleases [75]. We also have shown that fluorescein (FITC) terminated PEG chains are able to solubilize SWNTs with the aromatic FITC domain $\pi^{-} \pi$ stacked on the nanotube surface, yielding SWNTs having visible fluorescence which are useful for biological detection and imaging [76]. Furthermore, other aromatic molecules such as porphyrin derivatives have also been used for noncovalent functionalization of CNTs [77].

Various amphiphiles have been used to suspend carbon nanotubes in aqueous solutions, with hydrophobic domains attached to the nanotube surface via van der Waals forces and hydrophobic effects, and polar heads for water solubility [78]. We used Tween-20 and a Pluronic triblock copolymer to noncovalently functionalize nanotube surfaces to reduce the nonspecific binding of proteins in the case of SWNT-based biosensors [14]. Pluronic tri-block polymer was used by Cherukuri et al. to solubilize SWNTs for in vivo experiments [50]. However, the Pluronic coating is not sufficiently stable and is

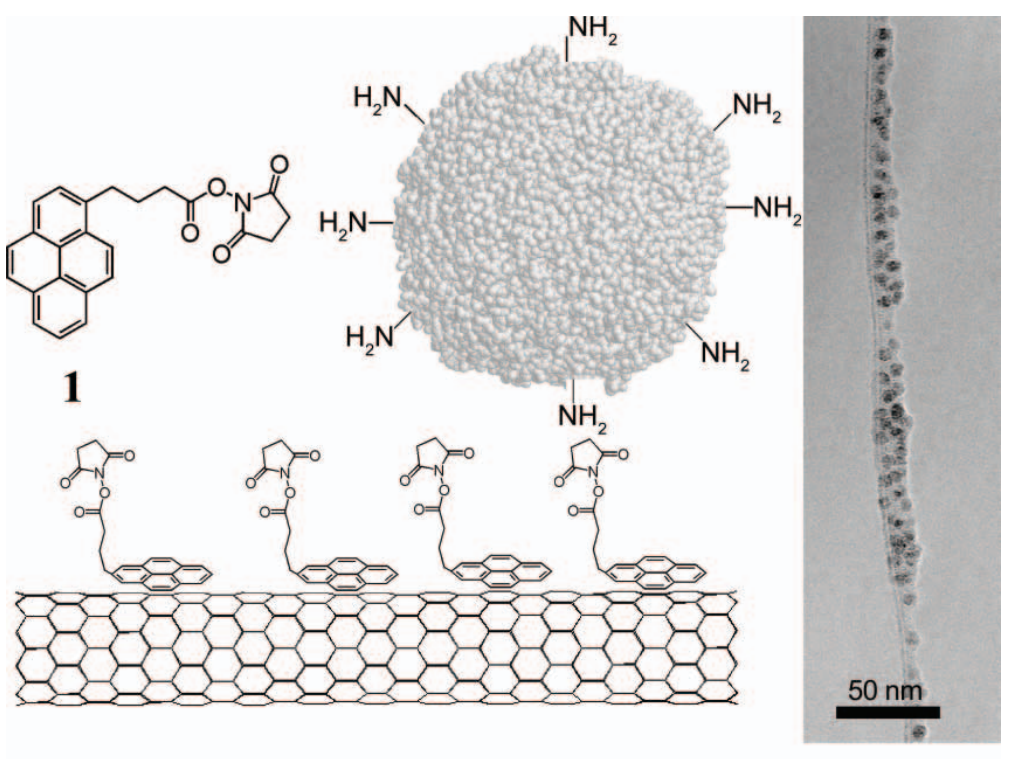

(a)

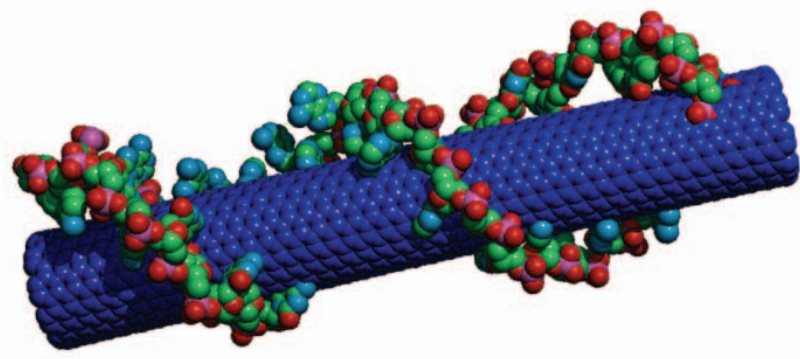

(b)

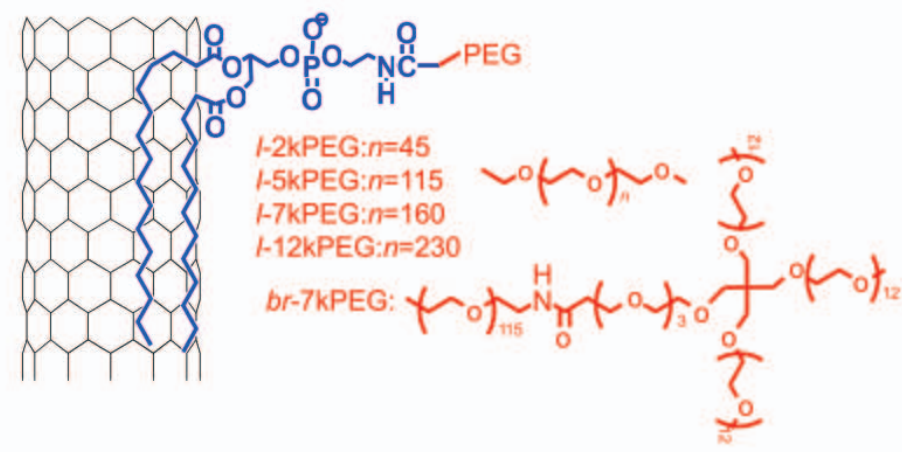

(c)

Figure 3 Schemes of noncovalent functionalization of carbon nanotubes. (a) Proteins are anchored on the SWNT surface via pyrene $\pi-\pi$ stacked on a nanotube surface. Right: A transmission electron microscope (TEM) image of an SWNT conjugated with proteins. Copyright 2001 American Chemical Society [70]. (b) An SWNT coated by a single-stranded DNA via $\pi-\pi$ stacking. Copyright 2005 the National Academy of Sciences [20]. (c) An SWNT functionalized with PEGylated phospholipids. Both linear PEG (I-PEG) or branched PEG (br-PEG) can be used in this method. Copyright 2005 the National Academy of Sciences [45] 
quickly replaced by serum proteins once SWNTs are intravenously injected. Other traditional surfactants including sodium dodecyl sulfate (SDS) and Triton X-100 have also been used to suspend CNTs in water [79]. Carbon nanotubes solubilized by those amphiphiles with relatively high critical micelle concentrations (CMC) are typically not stable without an excess of surfactant molecules in the solution. Large amounts of surfactants may lyse cell membranes and denature proteins, and are therefore not useful in biological environments.

An ideal noncovalent functionlization coating on CNTs for biological applications should have the following characteristics. First, the coating molecules should be biocompatible and nontoxic. Second, the coating should be sufficiently stable to resist detachment from the nanotube surface in biological solutions, especially in serum having high salt and protein contents. The amphiphilic coating molecules should have very low CMC values so that the nanotube coating is stable after removal of most of the excess coating molecules from the CNT suspension. Lastly, the coating molecules should have functional groups which are available for bioconjugation with antibodies or other molecules to create various functional CNT conjugates for different biological applications.

Noncovalent functionalization of SWNTs by PEGylated phospholipids (PL-PEG) was developed by our group to meet the above requirements, including high water solubility of nanotubes and versatile functionalities (Fig. 3(c)) [18, 20, 35, 37, 44]. Phospholipids are the major component of cell membranes, and are safe to use in biological systems. The two hydrocarbon chains of the lipid strongly anchor onto the nanotube surface with the hydrophilic PEG chain extending into the aqueous phase, imparting water solubility and biocompatibility. Unlike nanotubes suspended by typical surfactants, PEGylated SWNTs prepared by this method are highly stable in various biological solutions including serum, and even under harsh conditions without requiring the presence of excess PL-PEG (e.g., they are stable without coating detachment upon heating in phosphate buffered saline at $70{ }^{\circ} \mathrm{C}$ for weeks). PL-PEGs with different PEG lengths and structures (linear vs. branched) can be used to obtain specific PEGylated SWNTs for desired applications. Conjugation of biological molecules can be effected by using the functional group (e.g., amine) at the PEG terminal. Relying on this functionalization strategy, we have succeeded in using SWNTs for a range of biomedical applications including biological sensing, imaging and drug delivery In vitro with cells or in vivo with animals [18, 20, 24, 35, 37, 44, 45, 51].

\section{Selective protein-protein interactions on CNTs and biosensor applications}

Functionalization strategies as presented above suggest that both single-walled and multi-walled carbon nanotubes may present scaffolds for biomolecule immobilization, allowing subsequent applications in biosensing, utilizing the intrinsic electronic or optical properties of CNTs for signal transduction. The remarkable physical properties of carbon nanotubes, including high surface area, semiconducting behavior, band gap fluorescence, and strong Raman scattering spectra, lend themselves well to measuring or detecting proximal or adsorbed biomolecule interactions along the carbon nanotube sidewall, at functionalized cap regions [80], and even within the nanotube shell [81]. Proximity of reasonably charged or polarized biomolecules yields gating effects on isolated semiconducting carbon nanotubes, or net semiconducting networks of CNTs, thus yielding field-effect transistors (FETs) capable of quantifying the degree of specific or nonspecific binding of biomolecules [14]. Moreover, the photoluminescent and Raman scattering properties of single-walled carbon nanotubes may be applied to biosensing, by specific conjugation of targeting ligands to SWNT tags, coupled with sufficient sidewall passivation in order to prevent non-specific binding (NSB). Owing to their length scale and distinctive structure, carbon nanotubes are of great interest for the development of highly sensitive and multiplexed biosensors for applications ranging from the laboratory to the clinic. 


\subsection{Non-specific and specific protein-nanotube interactions}

In 1999, Balavoine et al. reported the crystallization of streptavidin, a biotin-binding protein expressed in Streptomyces avidinii, on the hydrophobic surface of MWNTs. While stochastic binding of the $\sim 70$ $\mathrm{kDa}$ protein to the nanotube sidewall was the major observation, helical packing of a streptavidin monolayer was observed on occasion [82]. A similar observation was found for the HupR protein, derived from Rhodobacter capsulatus, suggesting that non-specific interactions between proteins and carbon nanotubes are common for such water-soluble biomolecules.

Our group was the first to report that the interaction between proteins and the CNTs sidewall is general, and may be ascribed to hydrophobic interactions between the exterior fullerene surface and regions of high hydrophobic residue density within the protein tertiary structure. As such, non-specific adsorption of proteins does not appear to be dependent upon protein isoelectric point (pI) and occurs in a variety of buffers and solvents [14, 70, 83, 84]. To date, non-specific adsorption of a variety of proteins, ranging in size and pI, has been observed on both single- and multi-walled carbon nanotubes (Fig. 4).

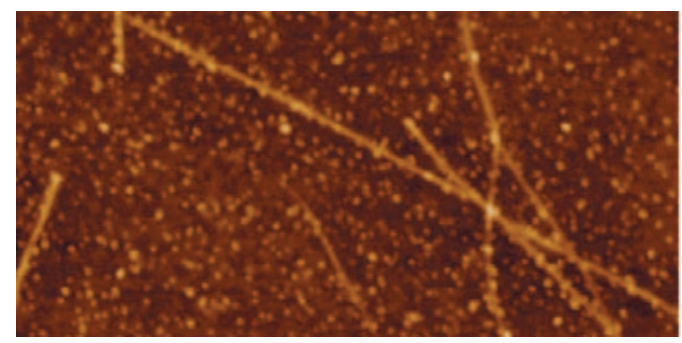

(a)

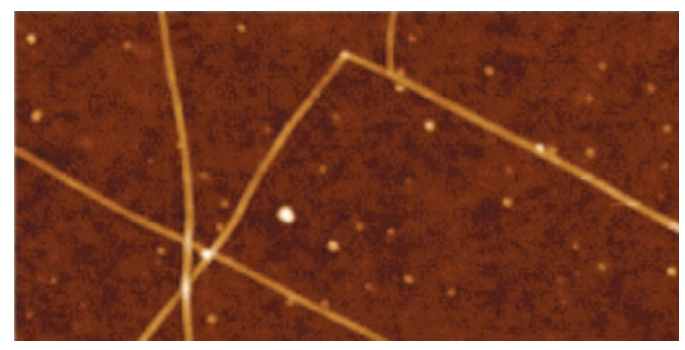

(b)

Figure 4 Tapping mode AFM images of the non-specific adsorption characteristics of streptavidin (SA) onto (a) bare single-walled carbon nanotubes (SWNTs) on $\mathrm{SiO}_{2} / \mathrm{Si}$. (b) Adsorption of SA onto SWNTS and $\mathrm{SiO}_{2} / \mathrm{Si}$ following application of Triton X-100. Copyright 2002 American Chemical Society [83]
The mechanism by which water-soluble proteins interact with bare carbon nanotubes was elucidated, both by the discovery of peptides binding directly to fullerene surfaces $[85,86]$, and by discovering methodologies to prevent protein adsorption. Our group demonstrated that amphiphilic coatings, containing PEG components, such as Tween-20 and Pluronics, were able to effectively decrease the hydrophobicity of the CNTs sidewall, thus reducing and often eliminating the non-specific adsorption of proteins [32, 83, 87]. This result suggested that non-specific protein-CNT interactions are highly dependent upon hydrophobic interactions [88], which are thermodynamically unstable in the presence of surfactants.

A variety of polymers and amphiphiles have been demonstrated for CNT passivation, including neutral molecules such as PL-PEGs [32], Triton X-100 [83], Tween-20, and Pluronics [14], all of which contain PEG components. Resistance to protein adsorption appears to scale with both the mass of the hydrophilic PEG block, as well as the number of PEG branches. Surfactant-coated carbon nanotubes immobilized on substrates demonstrate degrees of non-specific protein adsorption, ranging from partial inhibition of NSB [14] imparted by Triton X-100 (containing linear PEG $M_{\mathrm{n}} \sim 400 \mathrm{Da}$ ) to full inhibition by Tween-20 (containing branched PEG, $M_{\mathrm{n}} \sim 900 \mathrm{Da}$ ) $[14,83]$. Carbon nanotubes that are individualized and suspended in the aqueous phase present significantly higher sterically available surface area (by mass) for non-specific protein interactions, and thus require greater amounts of PEGylation for sufficient passivation. It was experimentally observed [32] that PL-PEG amphiphiles with PEG having $M_{\mathrm{n}} \sim 2000 \mathrm{Da}$ did not efficiently prevent nonspecific protein adsorption; however, longer linear PEG $\left(M_{\mathrm{n}} \sim 5000 \mathrm{Da}\right)$ or branched PEG $\left(M_{\mathrm{n}} \sim 8000 \mathrm{Da}\right)$ prevented most interactions.

While carbon nanotube-protein interactions can be observed via electron and force microscopies, utilization of such supramolecular systems for biosensing requires that protein activity and specificity remain intact. A comparative study of the enzymes soybean peroxidase and $\alpha$-chymotrypsin non-specifically adsorbed onto SWNTs revealed 
varying degrees of specific activity loss, seemingly proportional to protein melting temperature and loading density [89]. Loss of specific enzyme activity was correlated with inverse proportional changes in the number of $\alpha$-helices (increased) and $\beta$-sheets (decreased) upon adsorption onto hydrophobic SWNTs.

For applications of molecular recognition and readout based on carbon nanotubes, ligandtarget affinity must be maintained. Thus, the nonspecific immobilization of analyte proteins onto the hydrophobic nanotube sidewall is not desirable, owing to loss of function and lack of chemical control. As described above, several methods for specific nanotube functionalization exist; however, covalent modifications to the nanotube sidewall damage the interesting electronic and optical properties expected to be utilized as readout mechanisms in biomolecular detection.

In order to impart chemical functionality to SWNTs immobilized on substrates or suspended in aqueous media (a requirement for most biosensing applications) without hindering electrical or optical readout, noncovalent approaches are critical. Amphiphiles have been employed to impart robust functionality to CNTs as noted above, and ideal candidates for biosensing applications must simultaneously repel non-specific interactions and biofouling by including an inert hydrophilic spacer such as PEG.

Specific protein-nanotube conjugates, synthesized via supramolecular chemistry, have been reported in both surface-immobilized and solution phase methodologies. A proof of principle study demonstrated the chemically directed conjugation of streptavidin to bare SWNTs on $\mathrm{Si} / \mathrm{SiO}_{2}$, while nonspecific adsorption was prevented by a combination of Triton X100 and PEG [83]. Additionally, the surfactant Tween-20, adsorbed onto substratebound nanotubes, was covalently conjugated via carbonyldiimidazole to biotin, Staphylococcal protein A (SpA), and U1A antigen [14, 70], which imparted specific binding of streptavidin, immunoglobulin $\mathrm{G}$, and the monoclonal mouse antibody 10E6, respectively, while preventing non-specific adsorption of non-target proteins.

\subsection{Electrical detection of protein-nanotube interactions: Applications and mechanism}

Following the first demonstration of SWNTs acting as molecular sensors via field-effect doping by the gaseous species $\mathrm{NH}_{3}$ and $\mathrm{NO}_{2}$ [90], our lab amongst others set out to utilize field-effect transistors based on carbon nanotubes for label-free, highly specific biomolecule detection. As noted above, conjugation of biotin, Staphylococcal protein A (SpA), and U1A antigen to SWNTs [14, 70], amongst other ligands with specific binding characteristics, has been reported to impart specific binding of streptavidin, immunoglobulin $G$, and the monoclonal mouse antibody 10E6, respectively, allowing in situ direct detection of these analytes in the $\mathrm{nmol} / \mathrm{L}$ range via CNT FET devices (Fig. 5).

Surprisingly, in all cases of CNT FET-based detection, conductance across a semiconducting network of CNTs was reduced following specific analyte protein binding, regardless of analyte $\mathrm{pI}$ [14, 87]. Further studies revealed the importance of Schottky barrier modulation as a result of biomolecule adsorption/binding at nanotube-metal electrode contacts in detecting biomolecules with low net charge [87], thus elucidating the unexpected gating behaviors observed in FET biomolecule detection.

Understanding the Schottky barrier modulation mechanism of carbon nanotube FETs in biomolecule detection allowed for further improvements to be made in device architecture, thus allowing greater sensitivity and lower limits of detection to be coupled with specific binding, imparted by supramolecular ligand conjugations. Angular shadow mask deposition of $\mathrm{Au} / \mathrm{Cr}$ metal contacts onto semiconducting SWNT networks increased the contact area and reduced the contact thickness, raising hopes of increasing the Schottky barrier modulation component in FET conductance measurement of biomolecules (Fig. 6). As hypothesized, increased Schottky barrier area was correlated with improved sensor device characteristics, including a reduction in specific detection limit by four orders of magnitude, over a $\sim 1 \mu \mathrm{mol} / \mathrm{L}$ to $1 \mathrm{pmol} / \mathrm{L}$ range of analyte 


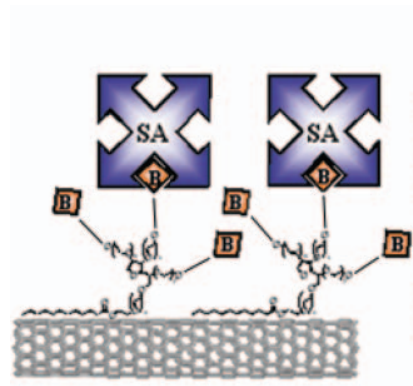

(a)

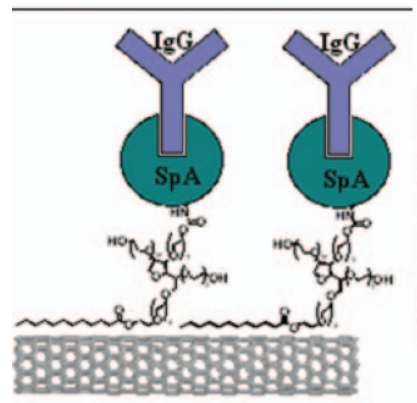

(d)

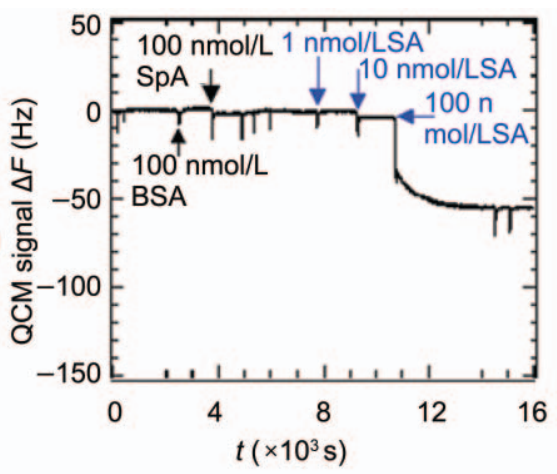

(b)

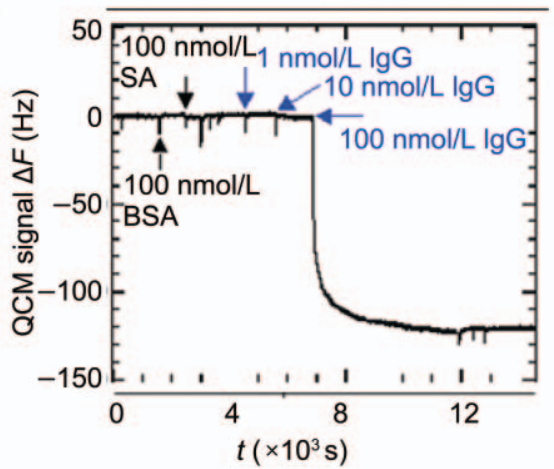

(e)

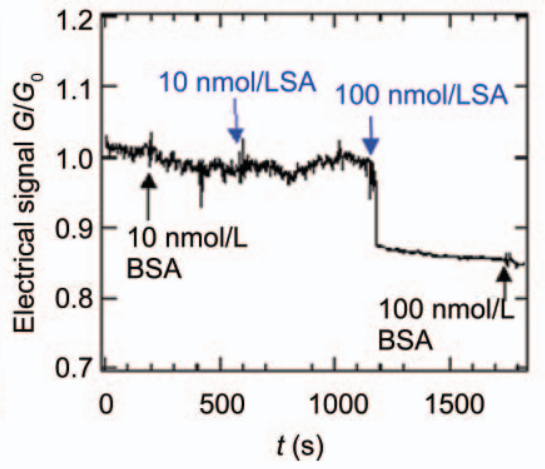

(c)

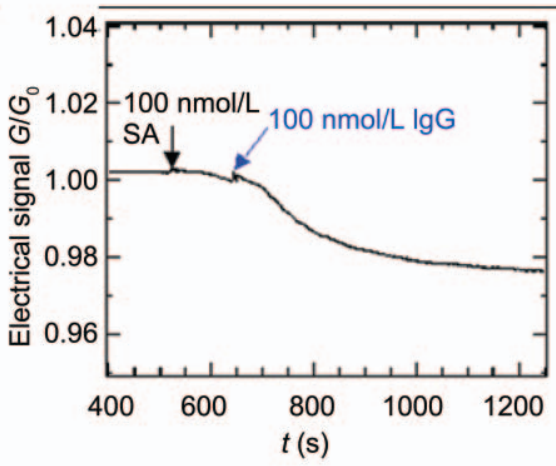

(f)

Figure 5 Specific chemical conjugation of biomolecules to SWNTs coated in Tween-20 surfactant, which prevents non-specific interactions, allows both quartz crystal microbalance (QCM) and FET measurement of target analyte binding. SWNTs functionalized by biotinylated Tween-20 (a) demonstrate QCM shifts dependent upon analyte, streptavidin, concentration (b), and analyte mediated conductance changes (c) as measured across a mat of SWNTs. (d) SWNTs may also be selectively coupled to Staphylococcal protein A (SpA) for selective binding of murine IgG as evidenced by QCM (e) and FET (f) measurements. Copyright 2003 the National Academy of Sciences [14]

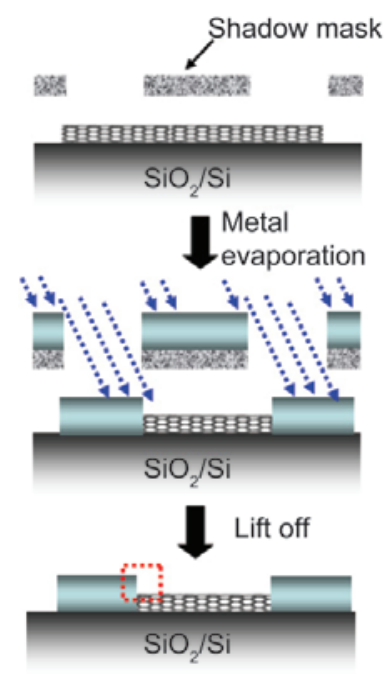

(a)

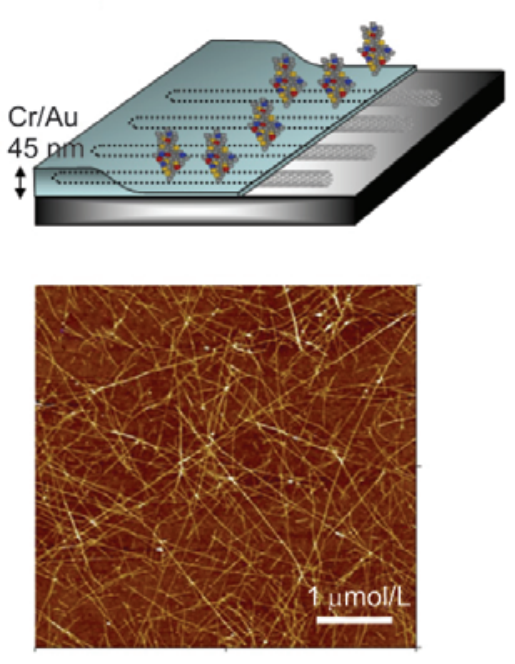

(c)
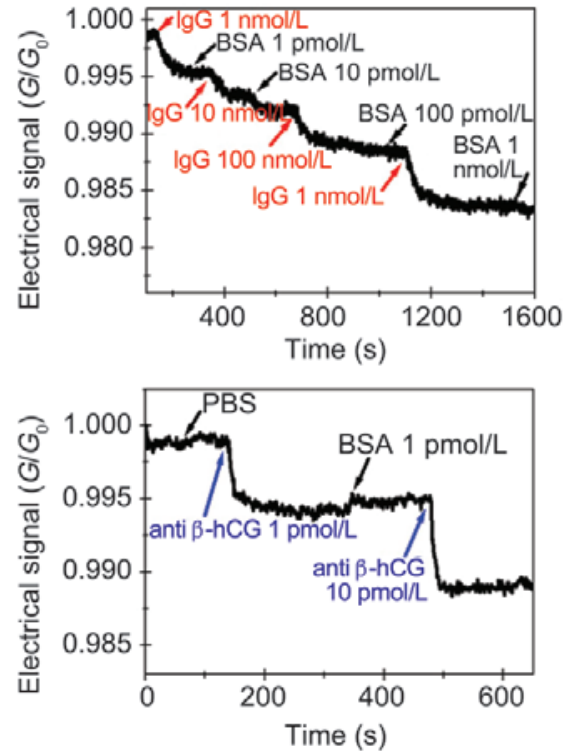

(b)

Figure 6 SWNT network device architecture for increased Schottky contact area affords biosensors of increased sensitivity: (a) Shadow mask deposition of $\mathrm{Au} / \mathrm{Cr}$ contacts at a $23^{\circ}$ angle onto a semiconducting SWNT network increases Schottky contact area; (b) FET devices fabricated from SWNT networks with high Schottky contact area demonstrate enhanced sensitivities and limits of detection in specific biomolecule detection by four orders of magnitude. Copyright 2006 American Chemical Society [91] 
protein concentration [91].

A variety of carbon nanotube FETs and electrochemical devices have been demonstrated for selective detection of oxidase and dehydrogenase activity, as well as for other enzymes and biomolecules of interest, in label-free fashion [92, 93]. However, the sensitivity of such devices in performing detection of biomolecules is limited by charge screening of both CNT-bound ligands and ions common in physiological buffers. Schottky barrier modulation and chemical gating effects of FETs are distance-dependent processes, thus reducing the utility of CNT FETs for complex (indirect) bioassays. Especially, troublesome for FET applications in detection of biomolecules is the incompatibility of common aqueous buffers with conductance modulated readout. The high ionic strength of physiological buffers, often required to retain protein structure and function, shields FET devices from charge effects of analyte biomolecules, thus reducing the simplicity and utility of this detection strategy. As a result, the detection of analyte concentrations in the $\mathrm{nmol} / \mathrm{L}$ to $\mathrm{pmol} / \mathrm{L}$ range has yielded poor signalto-noise ratios with these devices.

\subsection{Photoluminescent detection of proteins-based on semiconducting SWNTs}

Exploiting the interesting optical properties of semiconducting SWNTs, rather than monitoring their conductance in transistor devices, opens another route for sensitive and selective biomolecule detection using these extraordinary materials. SWNT band gap fluorescence [23] has been explored as a methodology for NIR-imaging of both In vitro and in vivo biological systems [17, 24, 26, 50, 94, 95], and holds promise for In vitro biomolecule detection assays in both direct and sandwich-assay formats [96 -98]. SWNT NIR fluorescence does not photobleach under high excitation powers and benefits from the negligible auto-fluorescence contributions of other assay components in the NIR range. SWNT fluorescence also demonstrates a large Stokes shift compared with traditional fluorophores, and allows a range of excitation energies to be used.

As described above, aqueous phase processing of SWNTs is made possible by PEGylated amphiphiles, which reduce biofouling and provide sites of functionality for ligand conjugation to the SWNT tags. Recently, our group has demonstrated specific and sensitive detection of biomolecules in sandwichassay format, using the band gap photoluminescence of SWNTs as NIR fluorophores, with sensitivity from the micromolar to the picomolar range (unpublished results). SWNT NIR fluorescence may be multiplexed via microarray printing technology, and unique SWNT fluorophores may be obtained by chirality separation [74]. NIR fluorescence detection via SWNT fluorophores may facilitate high throughput bioassays with low background contributions and thus improved sensitivity over conventional techniques.

In addition to direct measurement of SWNT fluorophore emission in immunoassay formats, Strano and coworkers have sought to use band gap modulation and charge transfer effects via photoluminescence for transduction and quantification of biomolecules such as DNA and glucose. Noncovalent functionalization of SWNTs with 24-mer ssDNA and subsequent hybridization of cDNA in proximity to the SWNT surface alters the dielectric constant at the SWNT surface, and produces a $2 \mathrm{meV}$ increase in band gap energy [97], observed as a blue shift in emission. Such methodology yields a theoretical detection limit of $6 \mathrm{nmol} / \mathrm{L}$ for 24-mer DNA. Moreover, utilizing a similar noncovalent modification strategy, the same group demonstrated signal transduction via fluorescence quenching for measuring glucose concentrations at physiologically relevant conditions, from the micromolar to millimolar range [98]. Direct detection of protein binding events by relief of band gap fluorescence quenching has also been demonstrated. Satishkumar et al. demonstrated that small molecule quenchers may be removed from SWNT surfaces by avidin and albumin in a specific and non-specific manner, respectively, with detection limits in the micromolar range [99].

In addition to quenching of the inherent SWNT band gap fluorescence for sensor applications, specific detection of biomolecules by quenching may also be realized by applying the carbon nanotube as both a scaffold for recognition ligands and as a quencher of

\section{型 Springer}


small molecule fluorophores. An excellent example of such quenching assays is the use of molecular beacons in real-time polymerase chain reaction (PCR) applications. In comparison with commonly used molecular beacons, SWNTs-noncovalently functionalized by FAMlabeled ssDNA - demonstrate superior quenching in the unhybridized state, and thus improved signalto-noise ratios when hybridized to a complementary strand [100]. Additionally, this new class of beacon affords improved thermal stability and is general to a wide variety of fluorophores.

While SWNT NIR band gap photoluminescence is promising for biomolecule detection, several problems remain to be solved. While only semi-conducting SWNTs demonstrate band gap photoluminescence, separation, and isolation of these fluorophores from other nonfluorescing SWNT isomers is challenging. Moreover, the quantum yield of those SWNTs that do fluoresce in the NIR is dependent upon their chemical environment, and processing is required to avoid quenching and maximize quantum yield [101]. Signal transduction via band gap modulation and quenching suffers from the limits of spectral resolution, as well as photoluminescence intensity, which restricts the utility of these methods to analytes at relatively high concentration. Applications of SWNTs as quenchers are promising for detection of ssDNA hybridization, however additional work is necessary to monitor protein interactions by this method. Future elucidation and optimization of SWNT fluorescence in the NIR range, as well as isolation of semiconducting SWNTs [74, 102] may improve the photoluminescent detection limit of SWNT fluorophores in protein assays by many orders of magnitude.

\subsection{Surface-enhanced SWNT-Raman tags for highly sensitive detection of proteins}

To avoid the issues plaguing SWNT photoluminescence-based detection of proteins In vitro, our lab sought to utilize the intense Raman scattering cross section of SWNTs in immunoassay format. While methodologically similar to fluorescence-based sandwich assays [103-105] the application of SWNT Raman tags in lieu of traditional or nontraditional [106] fluorophores offers many potential benefits. In addition to scattering efficiencies that rival the quantum yield of organic fluorophores [26], the Raman scattering spectra of SWNTs are simple, with strong, well-defined Lorentzian peaks of interest, demonstrating FWHM of 1-3 nm. As such, the Raman scattering spectra of SWNTs are easily distinguishable from noise, and no "auto-scattering" is observed for conventional assay surfaces or reagents [32]. Photobleaching of SWNT Raman tags is not observed even under extraordinarily high laser powers, a reflection of the stability of the SWNT $\mathrm{sp}^{2}$ carbon lattice.

Surface-enhanced Raman scattering (SERS) [106] is a technique that may be applied to vastly increase the intensity of Raman active molecules in proximity to appropriately tuned surface plasmons, usually associated with gold, silver, or copper nanostructures [107]. Coupling the intense resonance enhancement of 1-D SWNT Raman tags with SERS presents the opportunity to extend the limit of detection of traditional fluorescence assays from approximately $1 \mathrm{pmol} / \mathrm{L}$ [108] to the femtomolar level or below. By fabricating a gold-coated assay substrate via electron beam evaporation and roughening the gold surface via annealing at $400{ }^{\circ} \mathrm{C}$ in $\mathrm{H}_{2}$ following analyte and tag binding, our group was able to demonstrate quantitative SERS over a large area. While such treatment would destroy most small, organic Raman active molecules, SWNTs are robust and are undamaged by the process. This strategy for SERS yielded a nearly 100-fold increase in SWNT Raman scattering intensity [32] (Fig. 7).

As previously discussed, noncovalent surfactant wrapping may be used to both functionalize and passivate SWNTs. Recently, our group employed SWNTs, suspended by linear PL-PEG-NH ${ }_{2}\left(M_{\mathrm{n}} \sim 5000\right.$ Da) and branched PL-mPEG $\left(M_{n} \sim 8000 \mathrm{Da}\right)$ (Fig. 7), coupled to goat anti-mouse immunoglobulin $\mathrm{G}(\mathrm{GaM}$ $-\operatorname{IgG})$ for specific detection in immunoassays. To test the selective binding and non-specific behavior of such conjugates, a variety of analyte proteins were immobilized on SERS-active substrates, and, following incubation with GaM-IgG-SWNTs, selective detection of mouse IgGs was observed (Fig. 8). Extending this methodology to concentrationdependent sandwich immunoassays, we have been able to push limits of detection to $1 \mathrm{fmol} / \mathrm{L}$ of model 


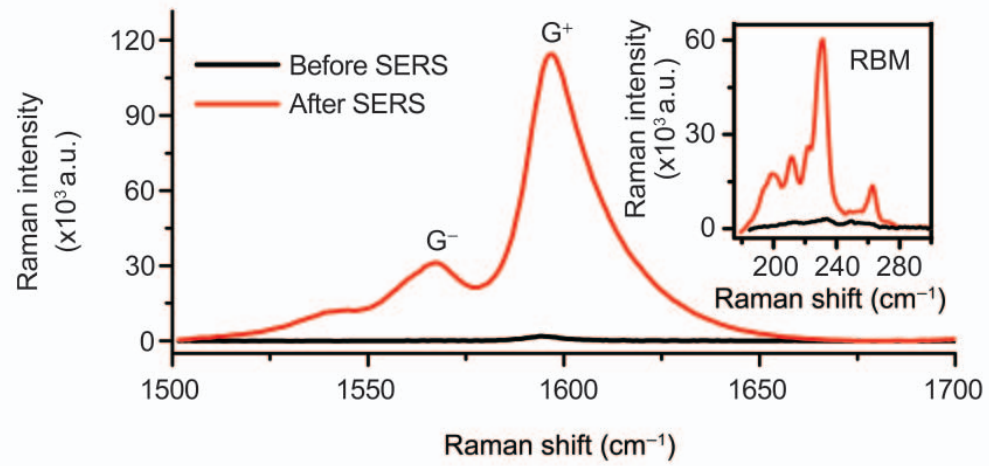

(a)

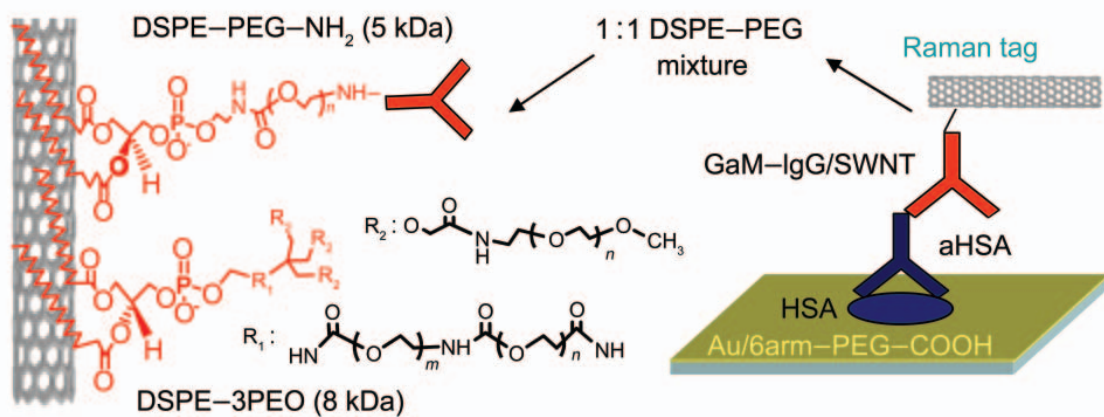

(b)

Figure 7 SWNT-antibody conjugates may be utilized in conjunction with SERS as bright Raman tags for sandwich assay protein detection: (a) preparation of a spatially uniform SERS substrate for SWNT Raman tag detection of biomolecules significantly increases Raman scattering intensity, thus improving signal-to-noise and reducing assay time; (b) SWNT-antibody conjugates were formulated by first suspending SWNTs in aqueous media via PEGylated surfactants, which provide functionality and prevent non-specific interactions to the hydrophobic SWNT surface, and subsequently coupled to antibodies via bifunctional cross-linkers. Such antibody-Raman tags have been used in direct and indirect immunoassays. Copyright 2008 Nature Publishing Group [32]

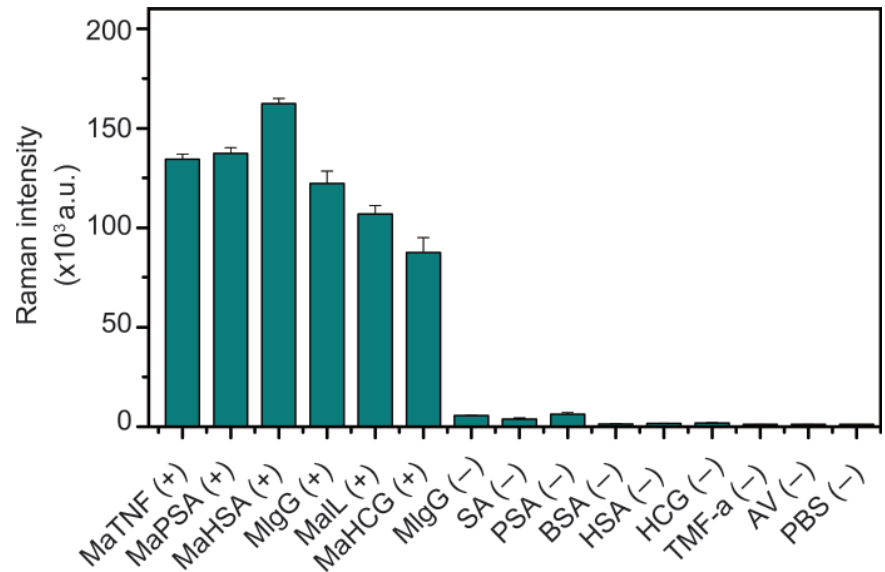

(a)

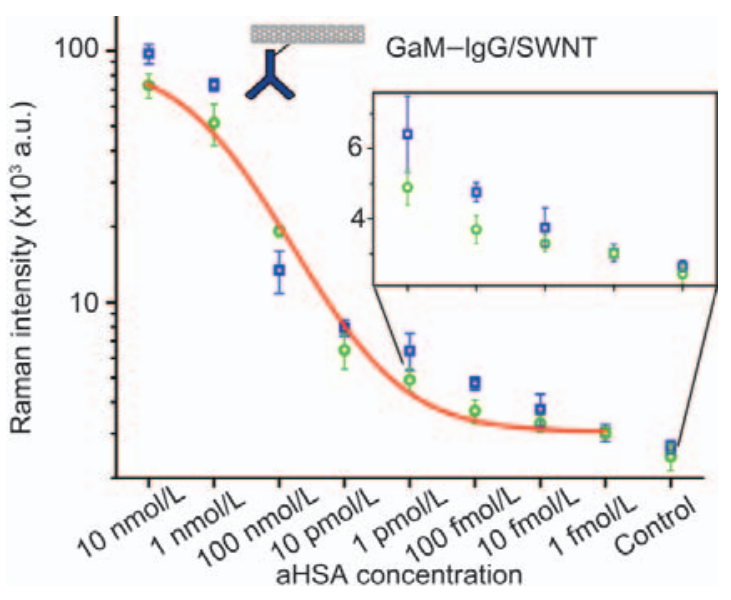

(b)

Figure 8 SWNT-Raman tags have been applied to immunoassays demonstrating both high selectivity and sensitivity: (a) SWNT-anti-mouse IgG conjugates were applied to direct detection of mouse IgGs, demonstrating excellent signal-to-noise and minimal cross-reactivity; (b) SWNTanti-mouse IgG conjugates were used as Raman tags for the indirect detection of mouse anti-human serum albumin (aHSA) IgG captured onto an SERS active substrate by HSA. A limit of detection of $1 \mathrm{fmol} / \mathrm{L}$ analyte was reproducibly observed (two separate trials are shown). The data are well fitted by a logistic regression (solid red curve, fit to data shown in green) allowing accurate quantitation of analyte over eight orders of magnitude. Copyright 2008 Nature Publishing Group [32] 
analyte, approximately three orders of magnitude better than common fluorescence methods. Ultrasensitive protein detection by SWNT Raman tags has been demonstrated not only for model analytes, but also for true biomarkers of human autoimmune disease [32] and cancer (unpublished results), with dynamic ranges over $6-8$ orders of magnitude (Fig. 8).

Biomolecule detection by SWNT Raman tags appears to be generalizable to systems other than high affinity antigen-antibody interactions, including biotin-streptavidin binding, protein A/G-IgG interaction and DNA hybridization [32]. By coupling the characteristic intense Raman scattering efficiency of 1-D SWNTs with quantitative SERS substrates and noncovalent strategies for both specific antibody conjugation and non-specific binding passivation, highly sensitive biosensors have been developed and demonstrated. Moreover, by taking advantage of highly multiplexable microarray technology, and employing isotopically labeled SWNTs (composed of pure ${ }^{12} \mathrm{C}$ and ${ }^{13} \mathrm{C}$, respectively) our group has demonstrated multicolor detection of multiple analytes simultaneously, utilizing only a single excitation source (Fig. 9). The application and utility of such sensitive, multiplexed biosensors remains to be fully explored, though with recent advances in biomarker discovery [109] there is much promise for detection and monitoring of early stage cancer.

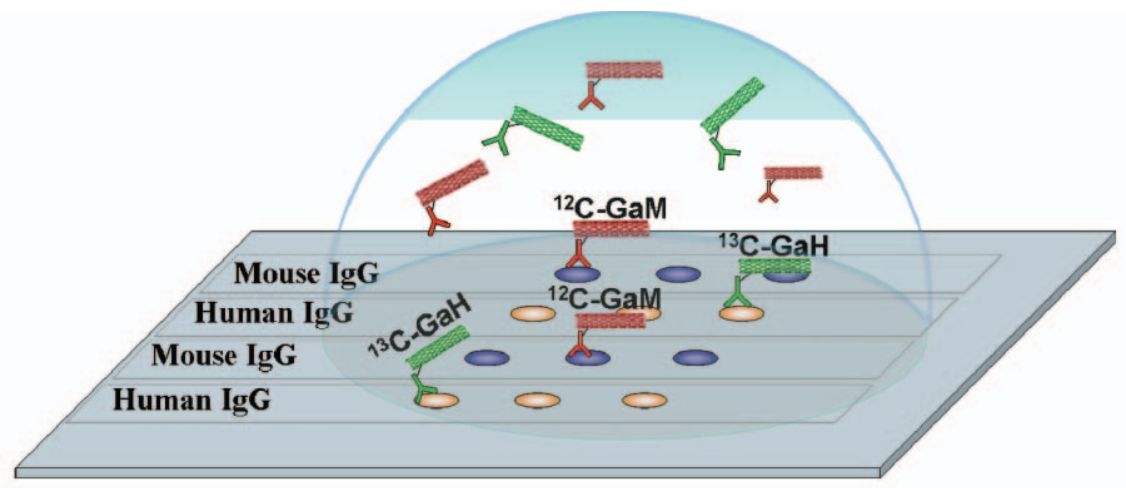

(a)

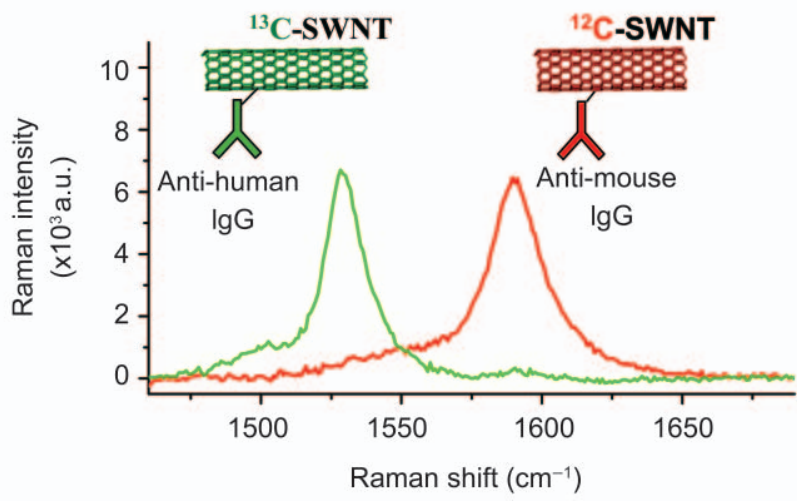

(b)

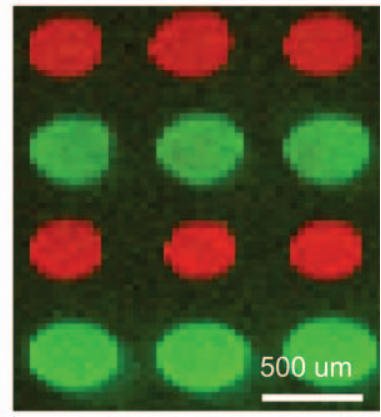

(c)

Figure 9 SWNT tags made from pure ${ }^{12} \mathrm{C}$ and ${ }^{13} \mathrm{C}$ feedstocks may be used for multicolor Raman-based protein detection: (a) Schematic diagram of a protein microarray employing multi-color SWNT tags for high throughput, multiplexed detection; (b) ${ }^{12} \mathrm{C}$ and ${ }^{13} \mathrm{C}$ SWNTs demonstrate easily resolvable G-band Raman scattering spectra; (c) direct Raman detection of mouse $\operatorname{lgG}$ (red) and human IgG (green) by ${ }^{12} \mathrm{C}$ and ${ }^{13} \mathrm{C}$ SWNT tags, respectively. Copyright 2008 Nature Publishing Group [32] 


\section{Toxicity of carbon nanotubes}

Safety is the first requirement of any material used in medicine. A large number of studies have been performed in the past several years to explore the potential toxic effects of carbon nanotubes. The conclusions of these reports varied drastically, showing a large dependence on the type of nanotube materials as well as functionalization approaches. Cell culture experiments and in vivo pilot studies conducted by various groups observed no obvious toxicity of properly functionalized carbon nanotubes $[15,53,58,72]$. On the other hand, raw carbon nanotubes were shown to be toxic to mice after inhalation into the lung $[39,40,110,111]$. Recent research showed that unfunctionalized, long MWNTs may pose a carcinogenic risk in mice [43]. As a result of the wide variety of reports, both the public and research communities are currently concerned about using carbon nanotubes for biomedical applications. It is thus critical and urgent to clarify the toxicity issue of carbon nanotubes. The current status is that toxicity appears to be dependent on the material preparation, especially geometry and surface functionalization. Well functionalized CNTs with biocompatible surface coatings have been shown to be nontoxic In vitro to cells and in vivo in mice.

\subsection{In vitro toxicity of carbon nanotubes}

Even in cell culture experiments, the issue of toxicity of carbon nanotubes is still controversial. While inhibition of HEK 293 cell proliferation after exposure to SWNTs was reported by Cui et al. [38], Ding et al. observed that MWNTs induce cell cycle arrest and increase apoptosis/necrosis of human skin fibroblasts [41]. However, neither of these studies used functionalized carbon nanotubes. Apoptosis of T lymphocytes induced by oxidized MWNTs was observed by Bottini et al. [42]. However, simple oxidation is not enough to render carbon nanotubes soluble and stable in saline and cell media, and thus does not represent a biocompatible functionalization. Sayes et al. further reported that the toxicity of CNTs was dependent on the density of functionalization, with minimal toxicity for those heavily functionalized with the highest density of phenyl- $\mathrm{SO}_{3} \mathrm{X}$ groups [112]. These results are understandable because CNTs without proper functionalization have a highly hydrophobic surface, and thus may aggregate in the cell culture and interact with cells by binding to various biological species, including proteins, via hydrophobic interactions, and induce certain cell responses such as cell toxicity.

Other factors may also contribute to the observed toxicity of CNT samples In vitro. Surfactants, present in excess in the CNT suspensions, are known to be highly toxic to cells [113]. The metal catalyst content in CNTs should also be considered when the toxicity of carbon nanotubes is investigated [114]. Moreover, proper assays must be employed in toxicity tests to avoid interference of carbon nanotubes with the assay reagents $[115,116]$. For these reasons, In vitro toxicity assays of carbon nanotubes should be carefully designed and performed with well prepared and characterized materials, as well as suitable assay methods.

We and many other groups have successfully used well functionalized, serum stable carbon nanotubes for In vitro cellular uptake experiments without observing apparent toxicity $[17,18,20$, 5157]. Cells exposed to SWNTs, PEGylated by various PL-PEG amphiphiles, used in our work exhibited neither enhanced apoptosis/neurosis, nor reduced proliferation of various cell lines In vitro $[18,20$, 51]. Carbon nanotubes covalently functionalized by 1,3-dipolar cycloaddition developed by Prato et al. also appeared to be safe to the tested cell lines, including primary immune cells $[52,53]$. Carbon nanotubes with a biomimetic coating engineered by Bertozzi et al. were also nontoxic to cells [54, 55]. Several other independent groups also reported that CNTs coated by DNA, amphiphilic helical peptides and serum proteins were not toxic to cells $[26,56$, 57]. In very recent work, Jin et al. discovered that SWNTs taken up by cells via endocytosis exited cells through exocytosis without affecting the viability of cells [95]. It appears that raw CNTs and CNTs without serum-stable functionalization show toxicity to cells at moderate dosage, while serum-stable, functionalized CNTs show little toxicity even at high dosages. 


\subsection{In vivo toxicity of carbon nanotubes}

To address the possible side effects of CNTs on human health and our environment, researchers have investigated the toxicology of CNTs in animal models. Unfunctionalized raw CNTs have been intratracheally (IT) instilled into animals, showing obvious pulmonary toxicity including unusual inflammation and fibrotic reactions due to the aggregation of hydrophobic raw CNTs in the lung airways [39, 40,110,111]. Those results suggest that aerosol exposure of raw CNTs in the workplace should be avoided to protect human health. Nevertheless, toxicities observed by intratracheal instillation of large amounts of raw CNTs may have little relevance to the toxicology profile of functionalized soluble CNTs for biomedical applications, especially when they are administered through other routes such as intraperitoneal (IP) and intravenous (IV) injections, by which lung airways are not exposed to CNTs.

In a recent pilot study, Poland et al. noticed asbestos-like pathogenic behaviors such as mesothelioma associated with exposing the mesothelial lining of the body cavity of mice to large MWNTs (length 10-50 $\mu \mathrm{m}$, diameter 80$160 \mathrm{~nm}$ ) following intraperitoneal injection [43]. Despite the importance of this finding for potential negative effects of CNTs to human health, it should be noted that the MWNT materials used in this study were simply sonicated in $0.5 \%$ bovine serum albumin (BSA) solutions without careful surface functionalization and hence are not directly meaningful as far as the functionalized CNTs with biocompatible coatings recommended for biomedical applications are concerned. Furthermore, lengthdependent pathogenicity was observed, as no obvious toxic effect was observed for shorter and smaller MWNTs (length 1-20 $\mu \mathrm{m}$, diameter 10-14 $\mathrm{nm}$ ), indicating that the toxicology profiles of CNTs may significantly differ between CNTs of various sizes (diameter and length). It is worth noting that functionalized SWNTs used in typical biomedical research have length 50-300 $\mathrm{nm}$ and diameter 1-2 $\mathrm{nm}$, which are entirely different from the geometry of MWNTs used by Poland et al.
The first reported in vivo toxicity study of functionalized SWNTs was conducted by the Gambhir group and our group [58]. Both covalently and noncovalently PEGylated SWNTs were used in this study. Mice intravenously injected with PEGylated SWNTs $(\sim 3 \mathrm{mg} / \mathrm{kg})$ were monitored over four months, with systolic blood pressure, complete blood counts and serum chemistry recorded every month. Careful necropsy and tissue histology examinations were performed at the end of four months. Normal blood chemistries and histological observations were observed in this study, suggesting that functionalized biocompatible SWNTs may be safe for in vivo biological applications. Another separate study by our group showed similar results, suggesting that PEGylated SWNTs are slowly excreted from the body following systemic distribution in mouse models, without exhibiting obvious toxicity in the process [45]. Recently, Yang et al. showed in a three-month toxicity study that SWNTs suspended by Tween-80, which is probably not an ideal coating molecule, exhibited low toxicities to the tested mice at a very high dose $(\sim 40 \mathrm{mg} / \mathrm{kg})$ following IV administration. Such toxicity may be due to the oxidative stress induced by SWNTs accumulated in the liver and lungs [117]. The toxicity observed was dose-dependent, and appeared to be less obvious at lower doses $(2 \mathrm{mg} / \mathrm{kg}$ and $16 \mathrm{mg} / \mathrm{kg})$. Another recent report by the same group showed that their covalently PEGylated SWNTs, with much higher aqueous stabilities and biocompatibilities, exhibited an ultralong blood circulation half-life in mice [118]. Although the long-term toxicology of such "improved" SWNTs has yet to be determined, no acute toxicity has been reported even at a high dose (24 mg/ kg).

To fully address the toxicity concern of CNTs, further investigations - including animal models other than mice-and on larger scales, are still required. Moreover, the interactions between administered CNTs and the immune complement system, whose activation is an important first line of defense against foreign species, especially microbes, require more attention [119]. Moreover, increased efforts are needed not only from the chemical aspect i.e., further optimizing CNT surface chemistry and 
geometry for improved biocompatibility, but also from those with biological expertise, to systematically study the complete CNT toxicology profile in different animal models with different routes of administration.

\section{In vitro delivery of biomolecules by carbon nanotubes}

The work using carbon nanotubes for drug delivery in our group was triggered by an unexpected finding that functionalized CNTs are able to enter cells by themselves without obvious toxicity [15]. Similar results were published by the Prato group around the same time [36]. The CNT cellular uptake mechanism may differ depending on the functionalization and size of the CNTs, including endocytosis as reported by us and several other groups [15, 26, 34, 56, 95], or passive diffusion as observed by the Prato group when CNTs are functionalized by 1,3-dipolar cycloaddition [16, 120]. CNTs have been used to efficiently shuttle various biological cargoes, ranging from small drug molecules to biomacromolecules, such as proteins and DNA/RNA, into different types of cells. Once taken up by cells via endocytosis, SWNTs are able to exit cells through exocytosis [95].

\subsection{Delivery of small drug molecules by carbon nanotubes}

Small drug molecules can be covalently conjugated to CNTs for In vitro delivery. Fluorescent dyes and drug cargoes were simultaneously linked to 1,3-dipolar cycloaddition functionalized CNTs via amide bonds for the delivery of an anti-cancer drug [69] or an antifungal drug [52] into cells. In collaboration with our group, Feazell and Lippard used noncovalently PEGylated SWNTs (using PL-PEG, $M_{\mathrm{n}} \sim 2000 \mathrm{Da}$ ) as a longboat delivery system to internalize a platinum(IV) complex, a prodrug of the cytotoxic platinum( II ), into cancer cells [121]. The inert platinum(IV) prodrug compounds developed by the Lippard group are activated only after being reduced to the active platinum( II) form. SWNTs tethered with the platinum(IV) complexes through peptide linkages are taken into cancer cells by endocytosis and reside in cell endosomes, where reduced $\mathrm{pH}$ induces reductive release of the platinum( II ) core complex, thus killing the cancer cells. The cytotoxicity of the platinum(IV) complex increases over 100-fold after attachment to SWNTs. We have also conjugated paclitaxel, a commonly used anti-cancer drug, to branched PEG-coated SWNTs via a cleavable ester bond [37]. The SWNT-PTX conjugate was tested both In vitro and in vivo.

Beside covalent conjugation, novel noncovalent supramolecular chemistry for loading aromatic drug molecules onto functionalized SWNTs by $\pi$ $-\pi$ stacking has been uncovered in our lab (Figs. 10 (a) and 10(b)) [18]. Doxorubicin, a commonly used cancer chemotherapy drug, can be loaded on the surface of PEGylated SWNTs with remarkably high loading, up to $4 \mathrm{~g}$ of drug per $1 \mathrm{~g}$ of nanotube, owing to the ultrahigh surface area of SWNTs. The loading/binding is $\mathrm{pH}$ dependent and favorable for drug release in endosomes and lysosomes, as well as in tumor micro-environments with acidic $\mathrm{pH}$ (Fig. 10(c)). Similar drug loading behaviors have been reported for MWNTs [122], single-walled carbon nanohorns [123] and nano-graphene oxide [124, 125]. The supramolecular approach of drug loading on CNTs opens new opportunities for drug delivery.

Targeting ligands including folic acid [20, 126], peptides [18, 44] and antibodies [24, 127-129] have been used to target CNTs to specific types of cells In vitro or to tumors in vivo. Targeted drug delivery with CNTs requires conjugation of both targeting molecules and drug molecules to the same nanotube, and thus requires carefully designed strategies [18, 126]. In the work reported by Dhar et al., folic acid (FA) was linked to a $\mathrm{Pt}(\mathrm{IV})$ prodrug compound, and then conjugated to PEGylated SWNTs [126], yielding an SWNT-Pt(IV)-FA conjugate that showed enhanced toxicity to folate receptor (FR) positive cells but not to FR negative cells as the result of FA targeted delivery. For the delivery of aromatic drugs such as doxorubicin, which are directly loaded on the nanotube surface via $\pi-\pi$ stacking, the functional groups on the SWNT coating molecules (e.g., PL-PEG -amine) can be conjugated with targeting molecules such as Arg-Gly-Asp (RGD) peptide for targeted delivery (Fig. 10(a)) [18].

Besides drug conjugation and loading on the 


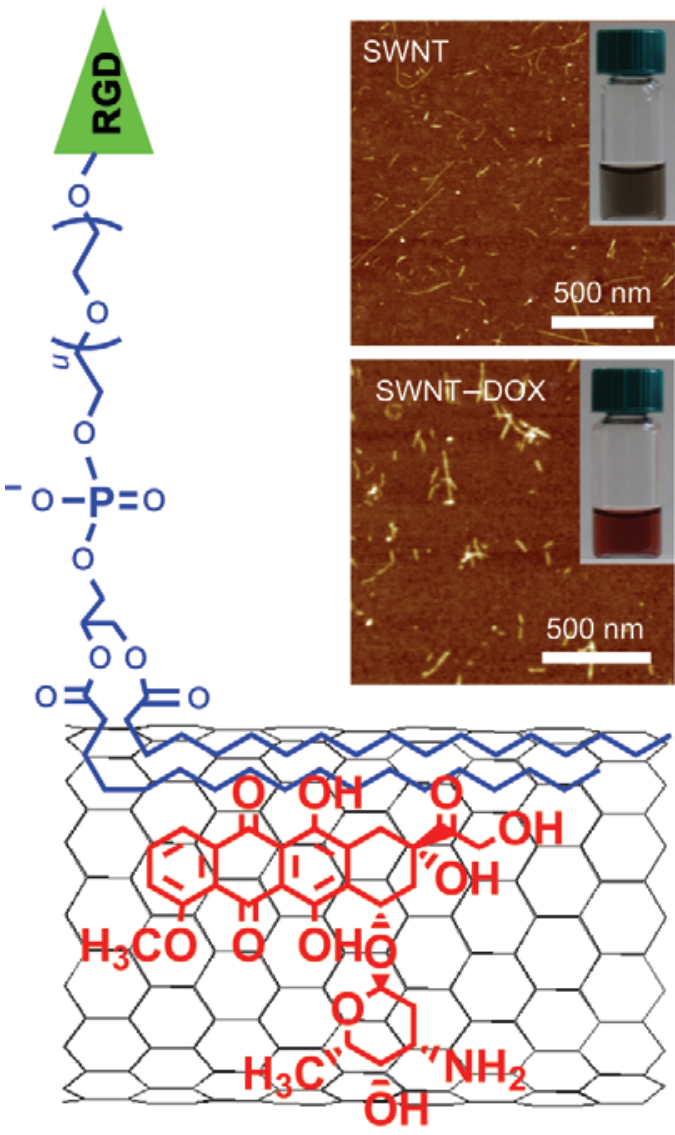

(a)

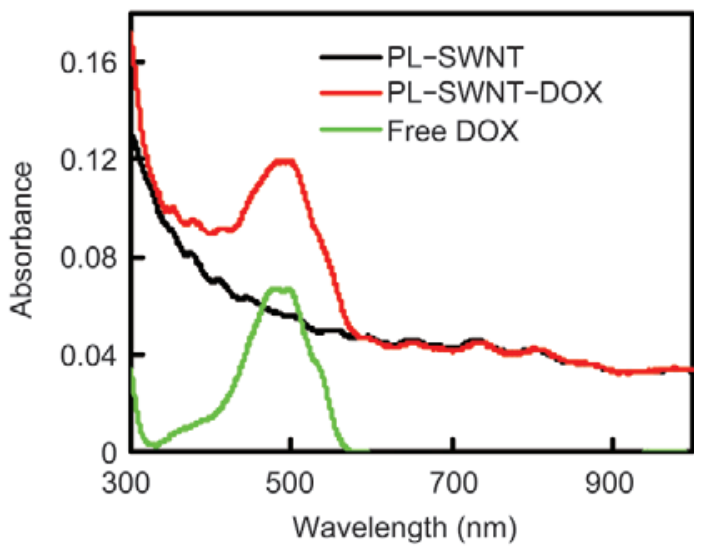

(b)

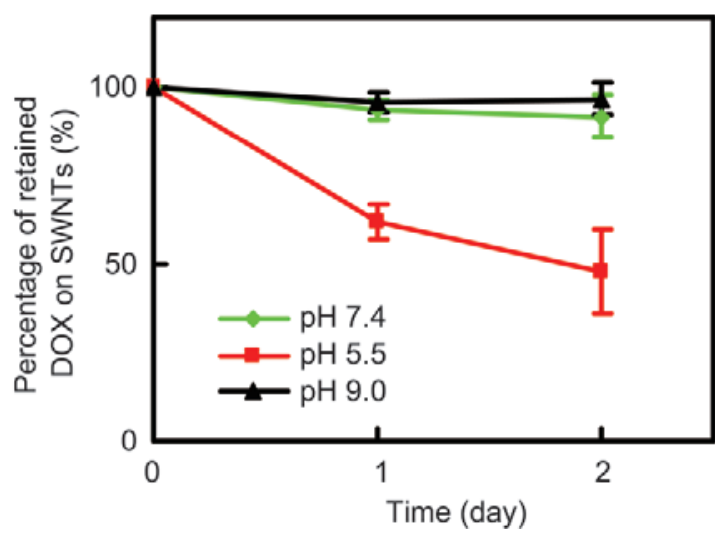

(c)

Figure 10 Supramolecular chemistry of functionalized SWNTs for efficient drug loading and delivery. (a) Schematic of doxorubicin (DOX) $\pi$-stacking onto a nanotube pre-functionalized by PL-PEG. Targeting ligands such as RGD peptide can be conjugated on the PEG termini for targeted drug delivery. Inset: AFM images of SWNT before (top) and after (bottom) DOX loading. The height of SWNTs increased after DOX loading. (b) UV-vis-NIR absorbance spectra of solutions of free doxorubicin (green), plain SWNTs (black), and DOX loaded SWNTs. (c) Release curves of DOX from SWNTs at different $\mathrm{pH}$. DOX loaded on SWNTs is stable at basic and neutral pH with very slow release but exhibits faster release in acidic environments. Copyright 2007 American Chemical Society [18]

external surfaces of nanotubes, the hollow structure of CNTs may allow the encapsulation of drug molecules inside nanotubes for drug delivery. Fullerene balls [130], metal ions [131], small compounds such as metallocenes [132], and even DNA molecules [133] have been encapsulated inside CNTs. Although a number of theoretical modeling studies predicted the insertion of biomolecules including chemotherapy drugs $[134,135]$ into CNTs, drug delivery by encapsulation of drugs inside CNTs has been rarely reported. Further experimental studies are still needed to examine the possibility of utilizing the encapsulation strategy in CNT-based drug delivery.

\subsection{Delivery of biomacromolecules by carbon nanotubes}

Unlike various small drug molecules which are able to diffuse into cells, biomacromolecules including proteins, DNA, and RNA rarely cross cell membranes by themselves. Intracellular delivery is thus required in order to use these molecules for therapeutic applications. Proteins can be either conjugated or noncovalently absorbed on nanotubes for intracellular delivery $[15,33]$. The hydrophobic surface of partially functionalized SWNTs (e.g., oxidized SWNTs) allows non-specific binding of proteins. After being translocated into cells by 
nanotubes, proteins can become bioactive once they are released from endosomes [33] .

CNTs can be modified with positive charges to bind DNA plasmids for gene transfection [2730]. Pantarotto et al. and Singh et al. used amineterminated SWNTs and MWNTs functionalized by 1,3-dipolar cycloaddition to bind DNA plasmids, and have achieved reasonable transfection efficiency [27, 29]. In the work of Gao et al., amine groups were introduced to oxidized MWNTs for DNA binding and transfection, successfully expressing green fluorescence protein (GFP) in mammalian cells. Although the MWNT-based method was less efficient than commercial gene transfection agents, such as lipofectamine 2000, the MWNTs exhibited much lower toxicity [30]. In another study carried out by Liu et al., polyethylenimine (PEI) grafted MWNTs were used for DNA attachment and delivery, which afforded comparable efficacy to the standard PEI transfection method with the benefit of reduced cytotoxicity [28].

Small interfering RNA (siRNA) is able to silence specific gene expression via RNA interference (RNAi) and has generated a great deal of interest in both basic and applied biology [136]. Although the viral-based siRNA delivery method has shown promise in animal models as well as clinical trials, the safety concern of viral vectors is significant. It is thus important to develop nonviral vectors for siRNA delivery [137, 138]. With a cleavable disulfide bond linkage between siRNA and SWNTs, we successfully delivered siRNA into cells by nanotubes and observed a gene silencing effect (Fig. 11(a)) [35]. We further showed that our SWNT-based siRNA delivery was applicable to those hardto-transfect human $\mathrm{T}$ cells and primary cells, which were resistant to delivery by conventional cationic liposome-based transfection agents (Figs. 11 (b) and 11(c)) [51]. Surface functionalizationdependent cell uptake of SWNTs was observed. Compared with SWNTs coated with long PEG (5.4 kDa) groups, shorter PEG (2 kDa) coated SWNTs with more exposed hydrophobic surface showed higher cellular uptake, which was favorable for siRNA delivery into cells (Fig. 11(d)). We propose that our SWNTs functionalized with short PEG (2 kDa) groups retain a certain hydrophobicity

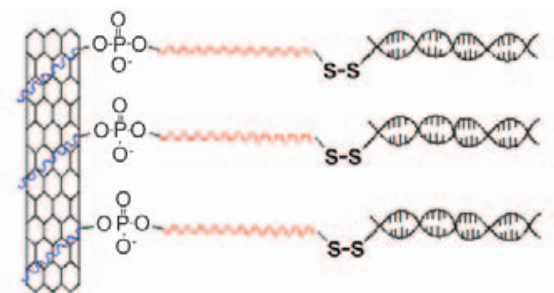

(a)

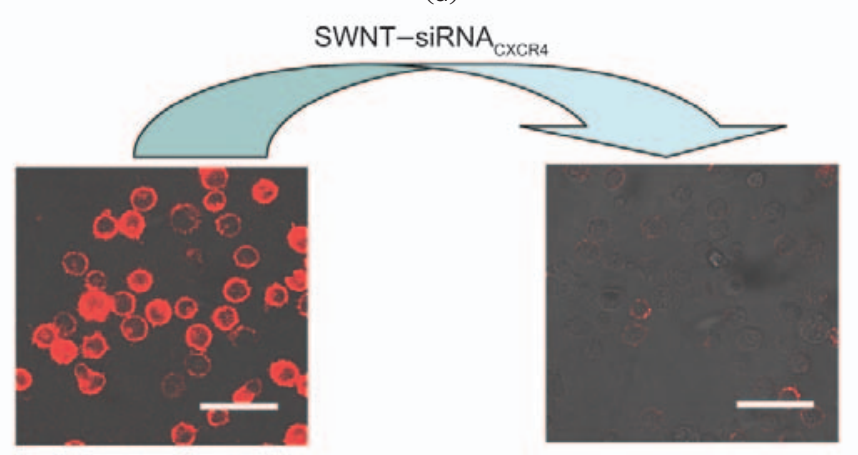

(b)

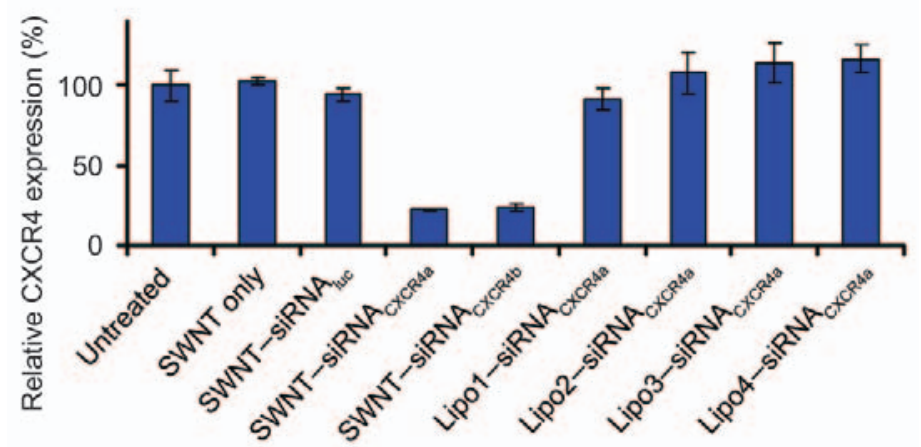

(c)
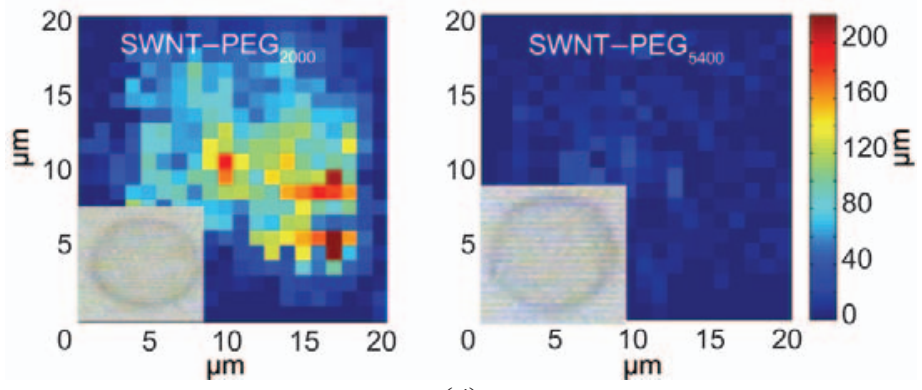

(d)

Figure 11 siRNA delivery by carbon nanotubes: (a) a scheme of SWNTsiRNA conjugation via disulfide linkage; (b) confocal images of untreated cells

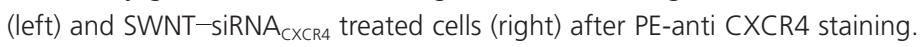
Scale bars: $40 \mu \mathrm{m}$; (c) CXCR4 expression levels on CEM cells three days after various treatments, including four types of liposomes (Lipo1-4) and luciferase (Luc) siRNA control; (d) G-mode Raman intensity maps of single CEM cells after incubation for $1 \mathrm{~d}$ in SWNTs functionalized by PL-PEG 2000 (left) and PL-PEG ${ }_{5400}$ (right) chains respectively. Inset: optical microscope images of CEM cells. Copyright 2007 Wiley-VCH [51] 
(due to incomplete coverage of nanotube sidewalls), which can cause binding and association with cells, resulting from hydrophobic interactions with hydrophobic cell membrane domains. Cell binding of SWNTs is an important first step for cellular entry via endocytosis. Our results suggest that balanced chemical functionalization schemes that impart sufficient aqueous solubility and biocompatibility to nanotubes, and also retain the ability of the nanotube to bind with cell surfaces are important for intracellular delivery of biomacromolecules by CNTs. Beside our work, other CNT-based siRNA delivery has also been reported, showing efficacy In vitro and even in vivo [139].

\section{In vivo biodistribution and long term fate of carbon nanotubes}

Encouraged by the success in using CNTs for In vitro sensing, drug delivery, and imaging, research in these fields has moved to in vivo animal research. The first critical questions to address are the biodistribution profile of CNTs after systemic administration into animals and whether there is any toxicity. In the past few years, in vivo biodistribution and pharmacokinetic studies have been carried out by a number of groups using different CNT materials, different surface functionalizations, and different tracking methodologies, thus obtaining varying and sometimes controversial results.

Radiolabeled ( ${ }^{111}$ In-DTPA) SWNTs and MWNTs functionalized by 1,3-dipolar cycloaddition were used by Singh et al. [46] and Lacerda et al. [47] to determine biodistribution. Surprisingly, after intravenous injection of CNTs into mice, they observed fast urinal clearance of CNTs, with the majority $(>95 \%)$ cleared out within $3 \mathrm{~h}$, and no uptake in RES organs such as the liver and spleen. Those phenomena were similar to the in vivo behavior of small molecules, but drastically differed from that expected of most nanoparticles with sizes exceeding the glomerular filtration threshold. To explain their results, the researchers proposed that despite their lengths, the small diameters of CNTs allowed for fast urinal excretion of CNTs. However, this conclusion is debatable considering well-characterized size- dependent protein biodistribution and excretion behavior (as shown in Table 1, proteins larger than 7-9 nm start showing high RES uptake and limited renal excretion) and also contradictory findings in a study reported by Choi et al. using quantum dots (QDs) [140]. It is found that the maximum size allowing fast urinal excretion of spherical QDs is $\sim 6 \mathrm{~nm}$, including coating molecules [140], which is indeed larger than the diameter of individual SWNTs (1-2 nm). However, the QDs were much smaller than the diameter of SWNT bundles $(10-40 \mathrm{~nm})$ [46] or MWNTs (20-30 nm) [47] used in these two CNT biodistribution studies. The reported fast CNT urinal excretion requires confirmation.

Several other labs have also studied the biodistribution of radiolabeled CNTs in mice. Wang et al. reported relatively slow urinal excretion and low RES uptake in their first study [141]. Later reports by the same group using ${ }^{14} \mathrm{C}$-taurine functionalized CNTs, however, revealed dominant and persistent liver accumulation of CNTs after intravenous injection [49, 142]. Another independent study by McDevitt et al. using antibody conjugated radiolabeled CNTs functionalized by 1,3-dipolar cycloaddition also showed high CNT uptake in the liver and spleen with slow urinal excretion [129]. A significant amount of CNTs remained in the body even after 15 days. We have also investigated the biodistribution of radiolabeled, PEGylated SWNTs, observing dominant SWNT uptake in RES organs, including liver and spleen, without rapid clearance [44]. Although the radiolabel method is a convenient way to examine the biodistribution of a substance, excess free radioisotopes in the radiolabeled CNT samples, if not completely removed, may lead to false results - especially for excretion-as free radioisotopes are small molecules that are rapidly excreted through urine after intravenous injection. Also, radiolabels could be gradually released from CNTs in vivo, and be slowly excreted in the free form. As a consequence, radiolabeling is not an ideal strategy to study the excretion and long term fate of CNTs.

Without using radiolabels, researchers have investigated the in vivo behavior of SWNTs relying on their intrinsic properties. Individual semiconducting 
Table 1 Biodistribution and pharmacokinetics of proteins with different sizes. Small proteins with diameter below 6-7 nm are quickly excreted through urinal clearance with very short blood circulation and whole body retention half-lives. Bigger proteins in contrast show high uptake in RES organs and much longer blood and whole body half-lives. They are unable to undergo fast urinal excretion because of their large sizes

\begin{tabular}{|c|c|c|c|c|c|c|c|}
\hline \multirow[t]{2}{*}{ Protein molecule } & \multirow[t]{2}{*}{$\mathrm{MW}(\mathrm{kDa})$} & \multirow[t]{2}{*}{$d(\mathrm{~nm})$} & \multicolumn{3}{|c|}{$\begin{array}{l}\text { Biodistribution } \\
(\%(I D / g) \text { at } 4 \text { h) }\end{array}$} & \multirow{2}{*}{$\begin{array}{l}\text { Blood half-life } \\
\text { (min) }\end{array}$} & \multirow{2}{*}{$\begin{array}{l}\text { Whole body } \\
\text { half-life (h) }\end{array}$} \\
\hline & & & Liver & Spleen & Kidney & & \\
\hline ScFv [143] & 30 & $5.3[140]$ & 1.3 & 0.9 & 0.8 & $<10$ & $\sim 3.8$ \\
\hline Fab' [143] & 50 & $6.0[144]$ & 1.3 & 1.8 & 21.5 & $\sim 30$ & $\sim 6.7$ \\
\hline $\mathrm{Sc}(\mathrm{Fv})_{2}[143,145]$ & 60 & $7.0[140]$ & 2.0 & 2.8 & 2.9 & 78 & $\sim 10$ \\
\hline$F\left(a b^{\prime}\right)_{2}[143]$ & 100 & - & 7.8 & 7.1 & 9.8 & $\sim 200$ & $\sim 20$ \\
\hline$\left[\mathrm{Sc}(\mathrm{Fv})_{2}\right]_{2}[145]$ & 120 & $9.3[140]$ & 7.0 & 6.2 & 3.6 & 170 & - \\
\hline $\lg (143,145]$ & 152 & 11 [144] & 18.7 & 18.0 & 4.7 & 330 & $\sim 80$ \\
\hline
\end{tabular}

SWNTs exhibit NIR photoluminescence, which has been used by Cherukuri et al. to track nanotubes in rabbits [50]. Without obtaining detailed biodistribution data, the authors observed SWNT photoluminescence signals in the liver, but not in other organs such as the kidney. In another study, Yang et al. used isotope ratio mass spectroscopy to examine the biodistribution of ${ }^{13} \mathrm{C}$ enriched unfunctionalized SWNTs over a month, showing high nanotube uptake in lung, liver, and spleen without apparent excretion within 28 days [48]. Taking advantage of the bright Raman scattering signatures of SWNTs, we used Raman spectroscopy to study the long-term fate of nanotubes in mice [45]. It was found that our PEGylated biocompatible SWNTs were predominantly accumulated in the liver and spleen after intravenous administration, but slowly excreted within months, probably via the biliary pathway into the feces. There could be a small portion of SWNTs with very short lengths that were excreted through urinal elimination, as indicated by the weak SWNT Raman signal observed in the mouse kidney and bladder.

Most importantly, we have systematically studied the relationship between PEG coating and the in vivo behavior of SWNTs. Prolonged blood circulation time is generally desired for drug delivery and tumor targeting. We have concluded that long PEG coatings on SWNTs generally confer a prolonged blood circulation half-life, reduced RES uptake and accelerated excretion (Fig. 12). Moreover, PEGs having a branched structure offer a more efficient coating on an SWNT surface than linear PEGs, and allow a longer SWNT blood circulation half-life, namely, $\sim 5 \mathrm{~h}$ for branched PEG compared with $\sim 2$ $\mathrm{h}$ for linear PEG of the same molecular weight (7 kDa) (Fig. 12) [45]. Another recent study by Yang et al. obtained an even longer blood circulation halflife (22 h) using covalently PEGylated SWNTs [118]. These results are thus important guides to future research into the use of carbon nanotubes for in vivo biomedical applications.

\section{In vivo tumor targeting and preliminary efforts towards in vivo cancer therapy}

In order to use CNTs for potential cancer treatment and/or imaging, targeting nanotubes to tumors is highly desirable. Both passive targeting, relying on the enhanced permeability and retention (EPR) effect of cancerous tumors, and active targeting guided by tumor targeting ligands, have been employed for various nanoparticle-based drug delivery systems. Thus far, there are two published papers reporting in vivo tumor targeting by CNTs conjugated with targeting ligands. We showed that efficient tumor targeting was achieved by conjugating a RGD peptide - which recognizes integrin $\alpha_{v} \beta_{3}$, known to be upregulated on various solid tumor cells and tumor vasculatures-to PEGylated SWNTs [44]. SWNTs with two different PEG coatings conjugated with both RGD peptide and radiolabels $\left({ }^{64} \mathrm{Cu}\right.$-DOTA) were

\section{尿策 Springer}




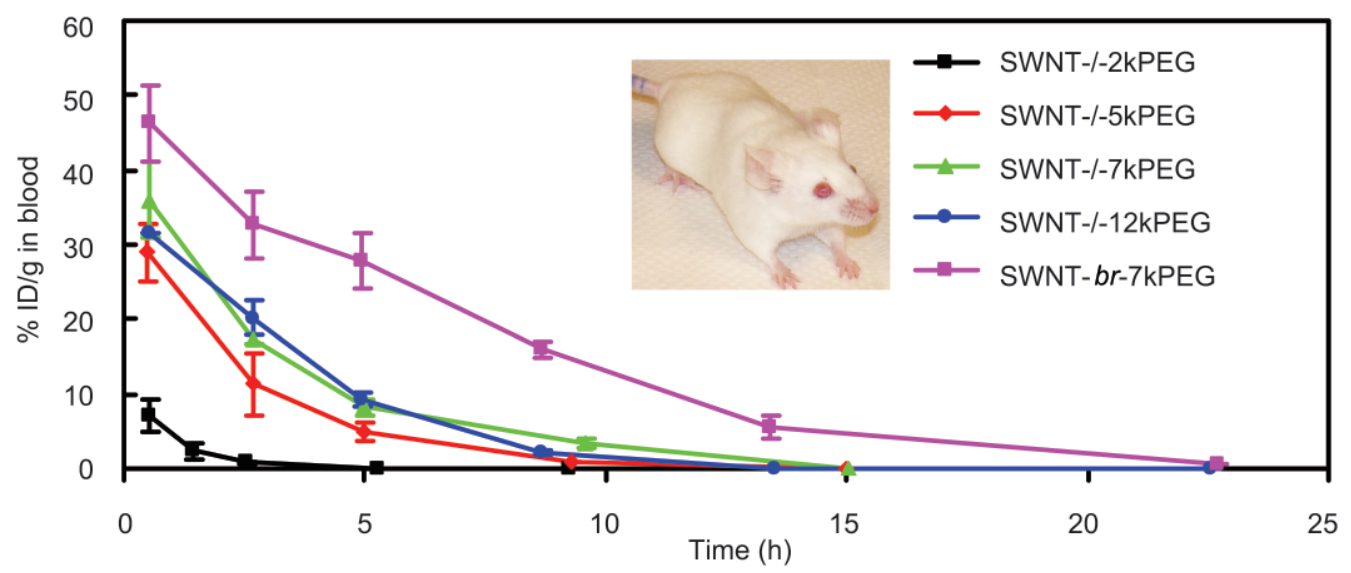

(a)

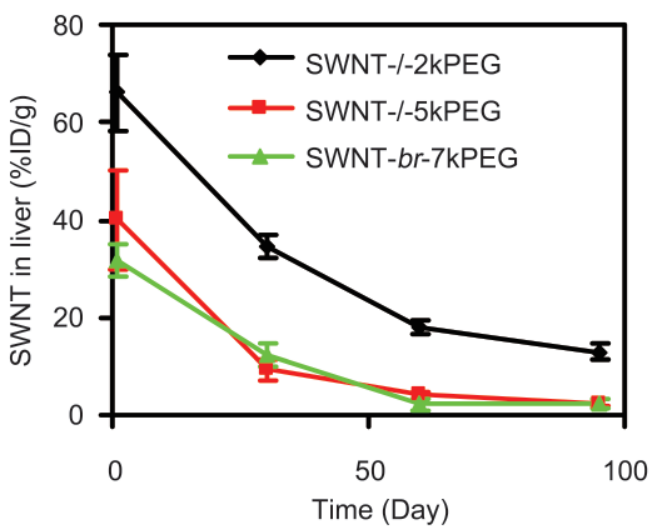

(b)

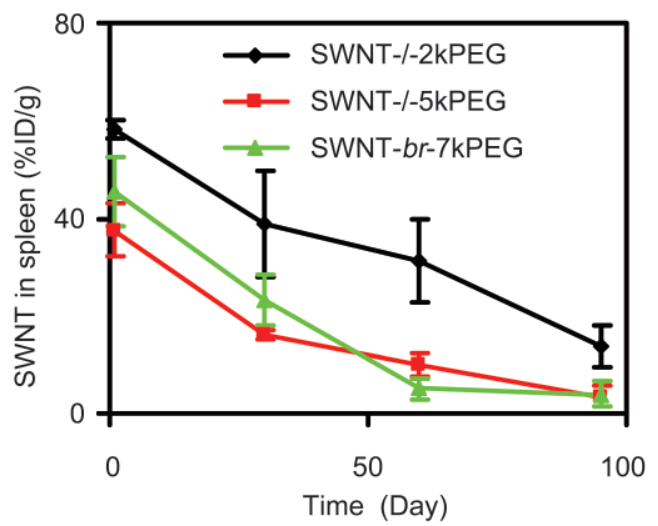

(c)
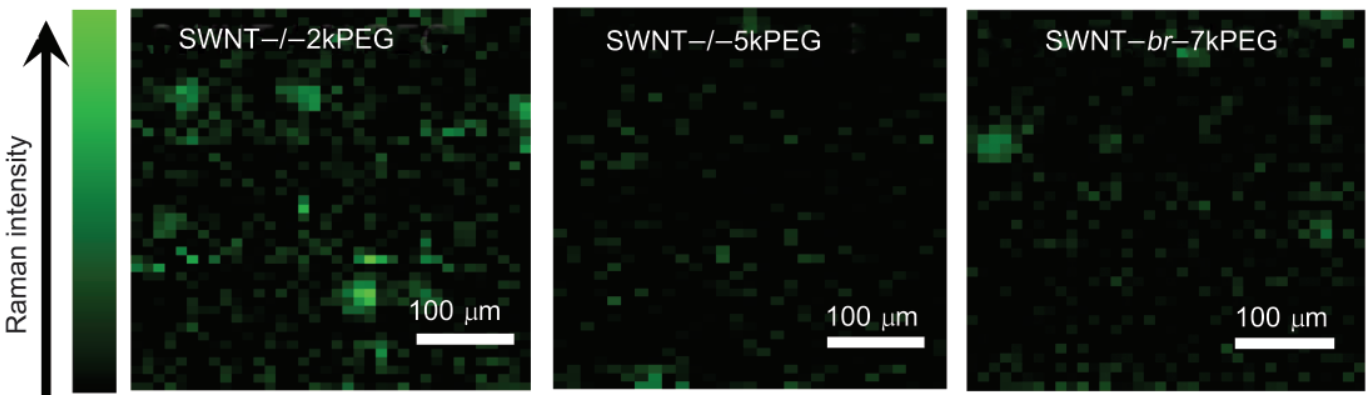

(d)

Figure 12 In vivo pharmacokinetics and long-term biodistribution of SWNTs with different PEG coatings (Fig. 2(c)) measured by Raman spectroscopy. (a) Blood circulation curves of different PEGylated SWNTs after intravenous injection to mice. Long and branched PEG coating on SWNTs prolongs blood circulation half-lives of nanotubes. SWNT levels in liver (b) and spleen (c) over time. SWNTs are slowly excreted from RES organs in a few months, with faster clearance rate for those with good PEG coating. Note that SWNTs have much lower uptakes in other organs (less then $2 \% \mathrm{ID} / \mathrm{g}$ ). (d) Raman images of mouse liver slices three months after SWNT injection. Much lower SWNT residues are observed in the liver of mice injected with nanotubes with more hydrophilic surface coating. Copyright 2008 the National Academy of Sciences [45]

intravenously injected into glioblastoma U87MG tumor-bearing mice, which were monitored by micro-positron emission tomography (micro-PET) over time (Fig. 13). RGD-conjugated SWNTs with a long PEG coating (SWNT-PEG ${ }_{5400}-\mathrm{RGD}$ ) exhibited a high tumor uptake of $\sim 13 \%$ of injected dose per gram tissue (\%ID/g), compared with $4 \%-5 \%$ ID $/ g$ obtained with plain SWNTs without RGD (SWNT$\mathrm{PEG}_{5400}$ ). Interestingly, we found that efficient tumor targeting could only be realized when SWNTs were 

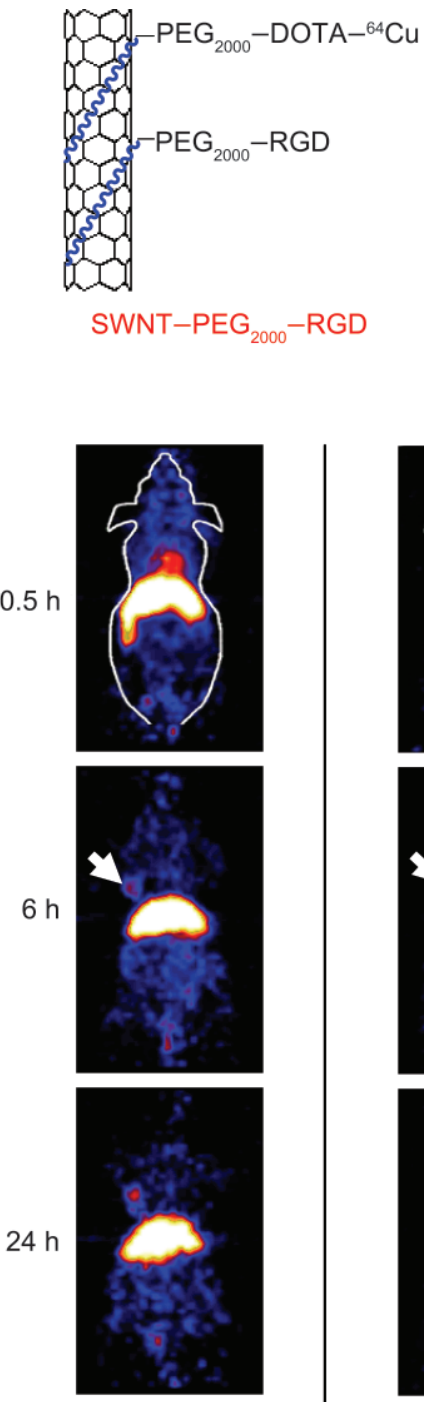

SWNT-PEG ${ }_{2000}-R G D$

U87MG

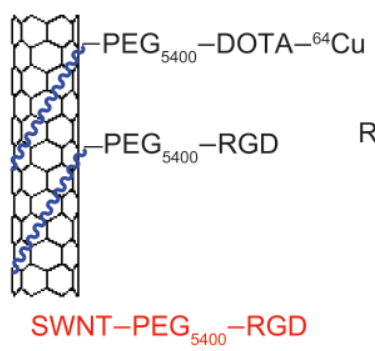

(a)

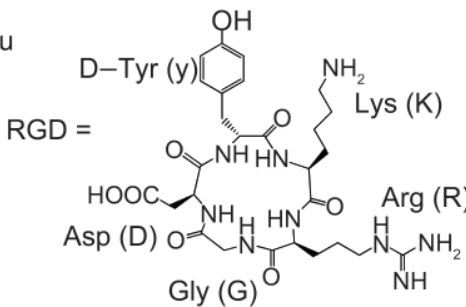

Gly (G)
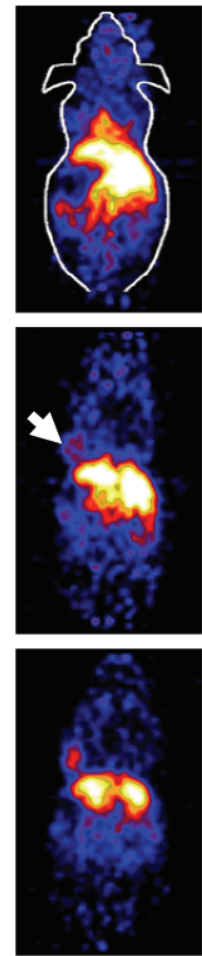

SWNT-PEG ${ }_{5400}-$ RGD w/RGD blocking U87MG

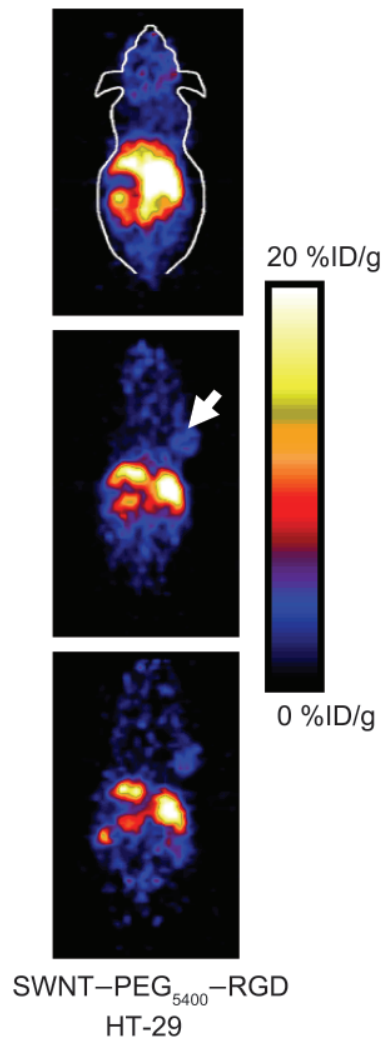

(b)

Figure 13 In vivo tumor targeting with SWNTs. (a) Scheme of PEGylated SWNTs with RGD conjugation and radiolabeling. (b) Micro-PET images of mice. Arrows point to the tumors. High tumor uptake ( 13\% ID/g) of SWNT-PEG ${ }_{5400}-R G D$ is observed in the U87MG tumor ( $2^{\text {nd }}$ column), in contrast to the low tumor uptake ( $1^{\text {st }}$ column) of SWNT-PEG $2000-R G D$. The $3^{\text {rd }}$ column is a control experiment showing blocking of SWNT$P G_{5400}-R G D$ tumor uptake by co-injection of free c(RGDyK). The $4^{\text {th }}$ column is a control experiment showing low uptake of SWNT-PEG ${ }_{5400}-R G D$ in integrin $\alpha_{v} \beta_{3}$-negative HT-29 tumor. Copyright 2007 Nature Publishing Group [44]

coated with long PEG (SWNT-PEG $5400-$ RGD) but not with short PEG (SWNT-PEG ${ }_{2000}-$ RGD). The latter had short blood circulation time, and thus lower probability of being trapped in tumors or to bind the tumor receptors. Our data suggest that surface functionalization of SWNTs is also important for tumor targeting in vivo. Another study carried out by McDevitt et al. [129] showed tumor targeting of
CNTs by antibody conjugation.

The first in vivo cancer treatment study with CNTs was reported by Zhang et al. using positively charged SWNTs to delivery therapeutic siRNA into cancer cells [139]. However, this was a proof-of-concept study, with SWNT-siRNA complexes directly injected into tumors, instead of systemic administration. Our recent work showed that paclitaxel (PTX), 
a commonly used chemotherapy drug, may be conjugated to branched PEG functionalized SWNTs via a cleavable ester bond (Fig. 14(a)) [37]. The SWNTPTX conjugate was tested in a 4T1 murine breast cancer model in mice, exhibiting improved treatment efficacy over the clinical Cremophor-based PTX formulation, Taxol® (Fig. 14(b)). Pharmacokinetics and biodistribution studies revealed longer blood circulation halflife and higher tumor uptake of SWNT-PTX than those of simple PEGylated PTX and Taxol ${ }^{\text {, }}$ consistent with the observed efficacies of different PTX formulations. The high passive tumor uptake of SWNT-PTX is likely due to the EPR effect. In addition, PTX molecules carried to RES organs (e.g., liver and spleen) by SWNTs were rapidly dissociated from nanotubes and excreted, diminishing the RES toxicity of this SWNT-based PTX formulation. Our work is the first to show that carbon nanotubes can be used for in vivo drug delivery for cancer therapy by systemic administration [37].

\section{Biological imaging using carbon nanotubes}

In addition to applications for drug delivery and treatment, the intrinsic optical properties of SWNTs make them useful as optical probes. Owing to their quasi 1-D nature, SWNTs exhibit strong resonance Raman scattering, high optical absorption and photoluminescence in the NIR range, all of which have been utilized for imaging in biological systems In vitro and in vivo.

\subsection{In vitro photoluminescence imaging}

Individual semiconducting SWNTs have small band gaps on the order of $\sim 1 \mathrm{eV}$, depending on the

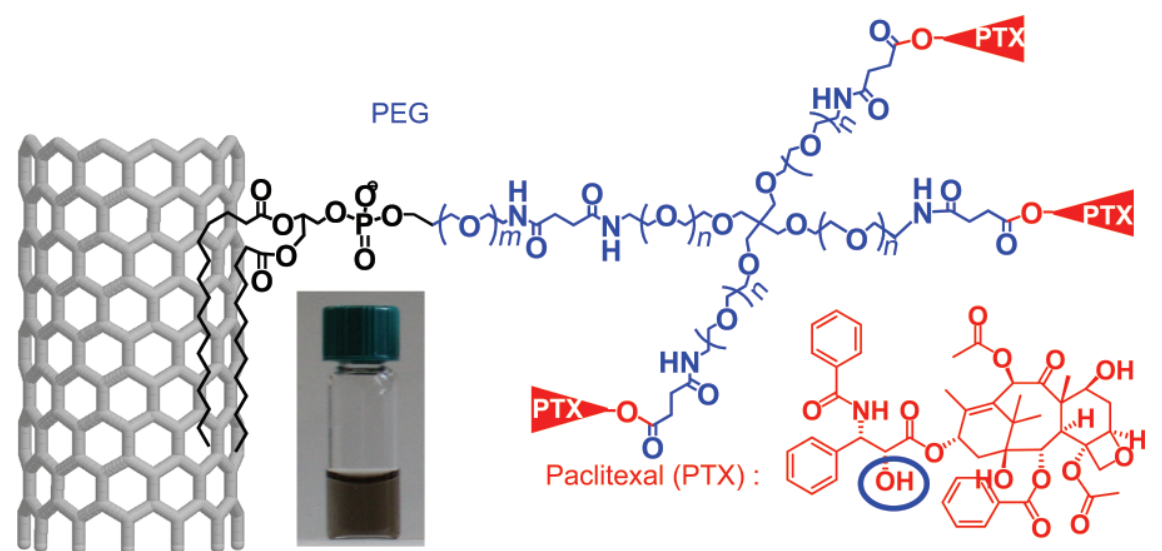

(a)

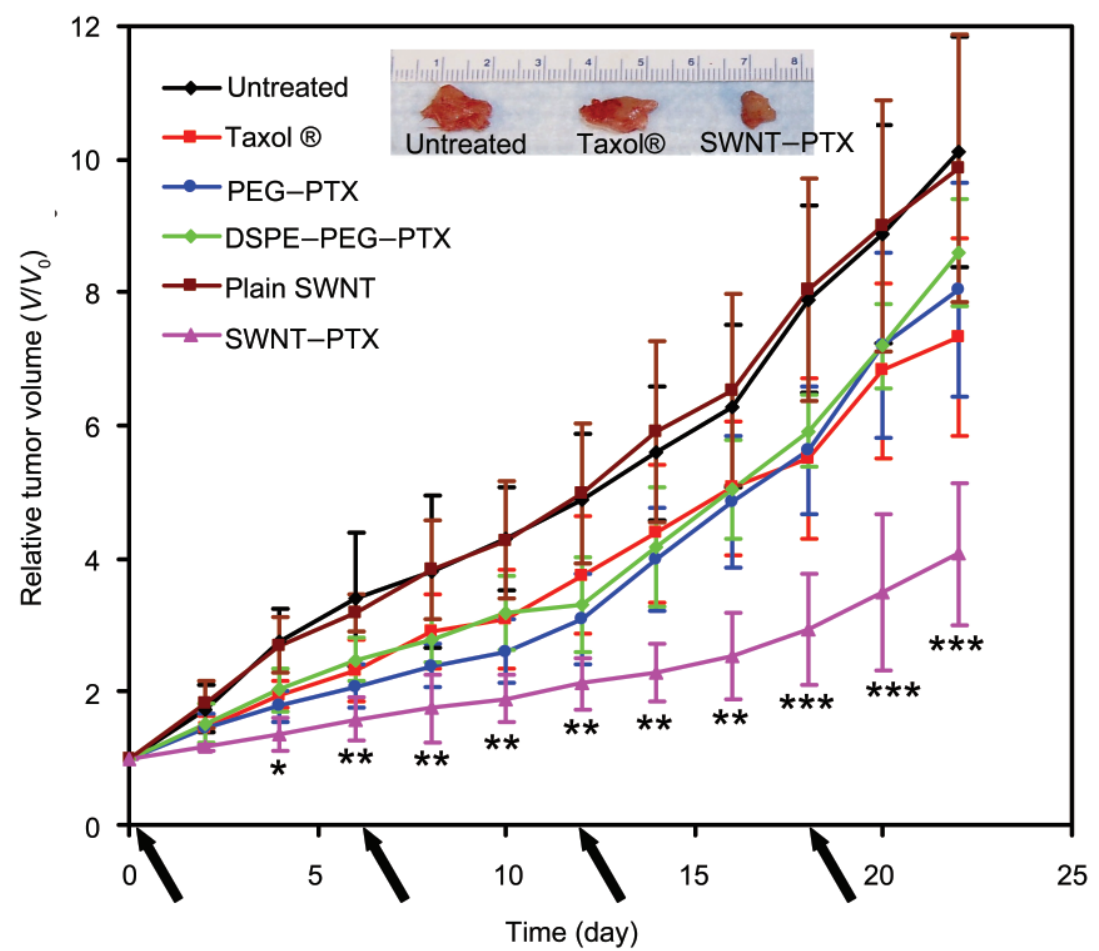

(b)

Figure 14 In vivo drug delivery with carbon nanotubes for cancer treatment. (a) Schematic illustration of paclitaxel conjugation to SWNT functionalized by phospholipids with branchedPEG chains. The PTX molecules are reacted with succinic anhydride (at the circled $\mathrm{OH}$ site) to form cleavable ester bonds and linked to the termini of branched PEG, via amide bonds. This allows for release of PTX from nanotubes by ester cleavage in vivo. (b) Tumor growth curves of 4 T1 tumor-bearing mice receiving the different treatments indicated. The same PTX dose ( $5 \mathrm{mg} / \mathrm{kg}$ ) was injected (on days 0, 6, 12, and 18, marked by arrows) for Taxol®, PEG-PTX, DSEP-PEG-PTX and SWNT-PTX. $p$ Values (Taxol@ vs SWNT-PTX): ${ }^{*} p<0.05, * * p<0.01, * * *$ $p<0.001$. Inset: $A$ photo of representative tumors taken out of an untreated mouse, a Taxol $\circledast$ treated mouse and an SWNT-PTX treated mouse at the end of the treatments. Copyright 2008 American Association for Cancer Research [37] 
diameter and chirality of a given nanotube. This band gap allows for photoluminescence in the NIR range $(900-1600 \mathrm{~nm})$ which is useful for biological imaging, due to the high optical transparency of biological tissue near 800-1000 nm and the inherently low autofluorescence from tissue in the NIR range [146]. SWNTs have a further advantage due to the large separation between the excitation (550-850 nm) and emission bands (900-1600 $\mathrm{nm}$ ). This spacing further reduces background from autofluorescence and Raman scattering.

O'Connell et al. [23] first demonstrated NIR photoluminescence from micelle-encapsulated SWNTs, yielding an estimated quantum efficiency of about $10^{-3}$. Relying on this intrinsic NIR photoluminescence, Cherukuri et al. imaged nonspecific uptake of SWNTs in phagocytic cells [17]. In more recent work, Jin et al. used NIR photoluminescence to track endocytosis and exocytosis of SWNTs in NIH-3T3 cells in real time [95]. In our lab, we developed bio-inert PEGylated SWNTs conjugated with antibodies as NIR fluorescent tags for selective probing of cell surface receptors [24]. Figure 15 shows NIR fluorescence images of (b) BT-474, which is HER2/neu positive, and (c) MCF-7, which is HER2/neu negative, treated with an SWNTherceptin conjugate. We observed ultralow NIR autofluorescence between different cell lines, demonstrating the advantage of SWNTs as an NIR fluorophore.

There is still work to be done in the application of SWNTs as effective fluorophores. Bioinert samples must be made with optimized quantum yields. Initial estimates of the quantum yield of SWNT suspensions were on the order of $10^{-3}$ or less [23,
147]. This seems to contradict studies on single SWNTs with much higher quantum yield estimates of up to 0.07 [148]. Many factors contribute to the quantum yield including exciton quenching by bundles [149], sidewall defects [150], and length [151]. Crochet et al. showed that the quantum yield of bulk SWNT suspensions could be increased by an order of magnitude by centrifugation in an iodixanol gradient to remove bundled nanotubes [152]. Careful preparation techniques, such as these, need to be applied in making suspensions of pristine, unbundled SWNTs in bio-inert coatings, such as PL-PEG, in order to fully realize their potential as

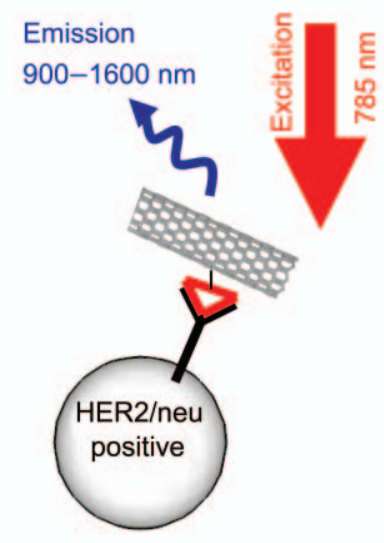

(a)

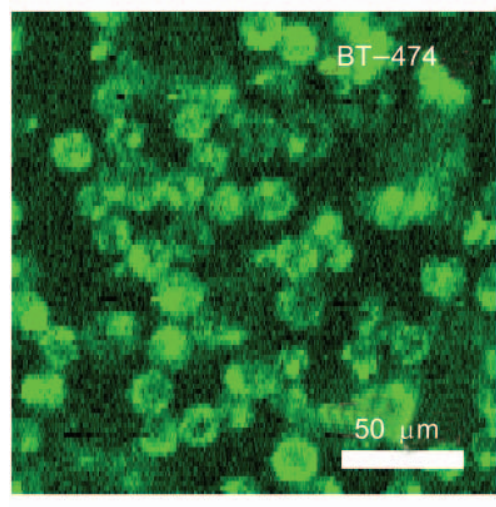

(b)
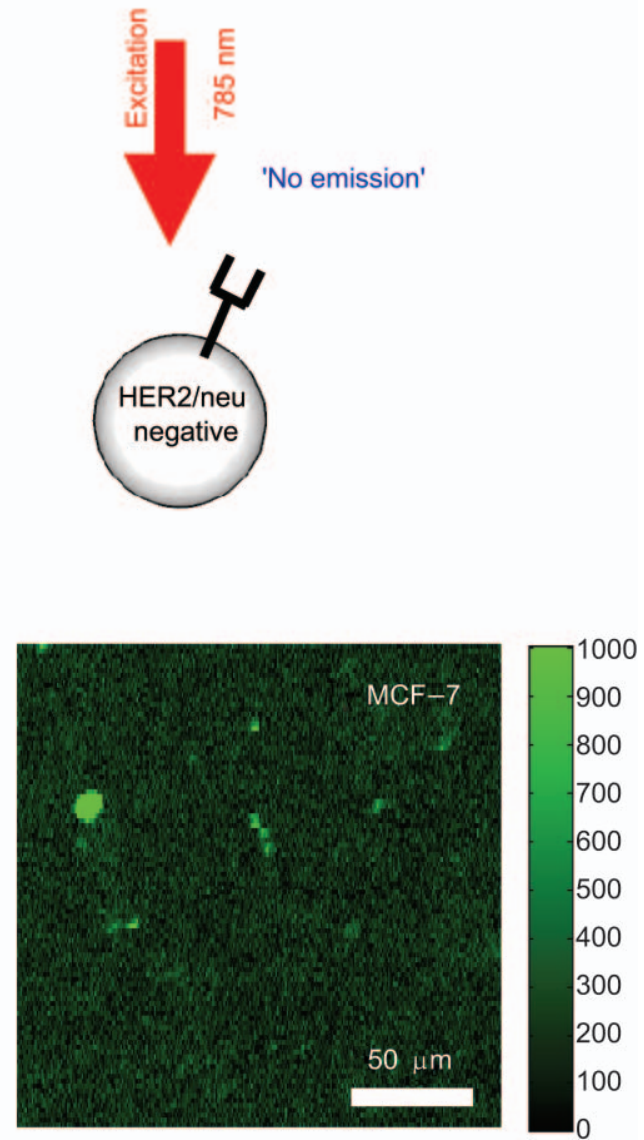

(c)
Figure 15 SWNT as NIR fluorescent labels. (a) Schematic of targeting cells with SWNTHerceptin conjugates to BT-474 (HER2/neu positive) and MCF-7 (HER2/neu negative) cells. (b) NIR photoluminescence image of BT-474 cells treated with the SWNT-herceptin conjugate. The high level of fluorescence signal indicates surface binding of the SWNT-Herceptin conjugate. (c) NIR photoluminescence image of MCF-7 cells. Very little NIR signal is seen owing to the low non-specific binding of the SWNT-Herceptin conjugate and low cellular autofluorescence. NIR photoluminescence images were taken using a homebuilt scanning confocal microscope with InGaAs detector. Photoluminescence was collected from 900-1600 nm. Copyright 2008 American Chemical Society [24] 
sensitive NIR fluorophores.

\subsection{In vitro Raman imaging}

Owing to their quasi 1-D nature, SWNTs exhibit strong resonance Raman scattering due to their sharp electronic density of states at the van Hove singularities. SWNTs have several distinctive Raman scattering features including the radial breathing mode (RBM) and tangential mode (G-band) [25], which are sharp and strong peaks that can be easily distinguished from fluorescence backgrounds, and are thus suitable for optical imaging. We and Heller et al. have used Raman microscopy to image SWNTs in liver cells, as well as tissue slices, using either the RBM peak or G-band peak of SWNTs [26, 45, 51, 58]. Our latest work showed that SWNTs with different isotope compositions exhibited shifted $\mathrm{G}$ band peaks, and thus could be used as multicolor contrast agents for multiplexed Raman imaging [127]. Cancer cells with different receptor expression profiles were selectively labeled with three isotopically unique formulations of "colored" SWNTs, conjugated with various targeting ligands including Herceptin (anti-Her2), Erbitux (anti-Her1), and RGD peptide, allowing for multicolor confocal Raman imaging of cells in a multiplexed manner using a single excitation (Figs. 16(c) and 16(d)). Raman signals of SWNTs are highly robust against photobleaching, allowing long term imaging and tracking [26, 45]. With narrow peak features, SWNT Raman signals are easily differentiated from the auto-fluorescence background. The SWNT Raman excitation and scattering photons are in the NIR region, which is the most transparent optical window for biological
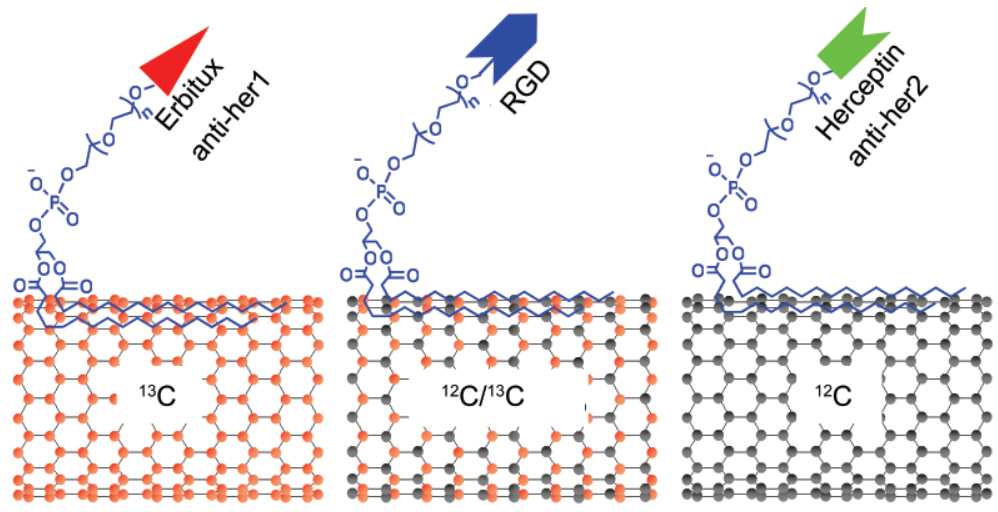

(b)

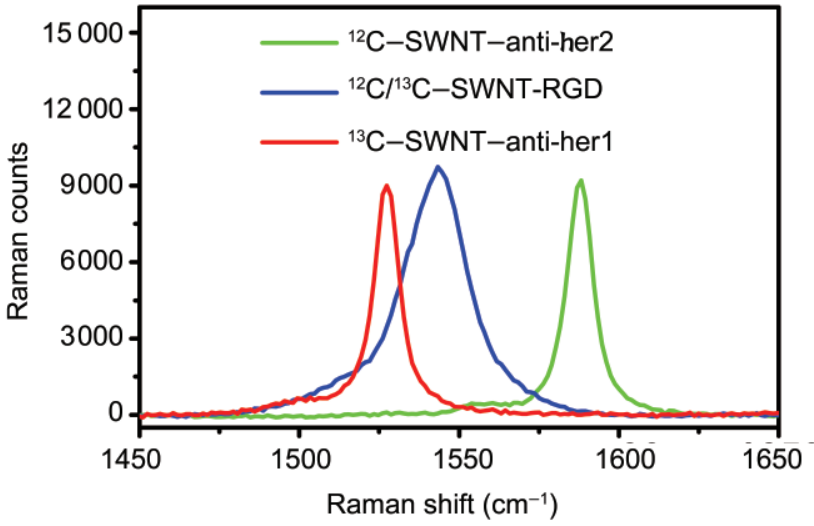

(b)

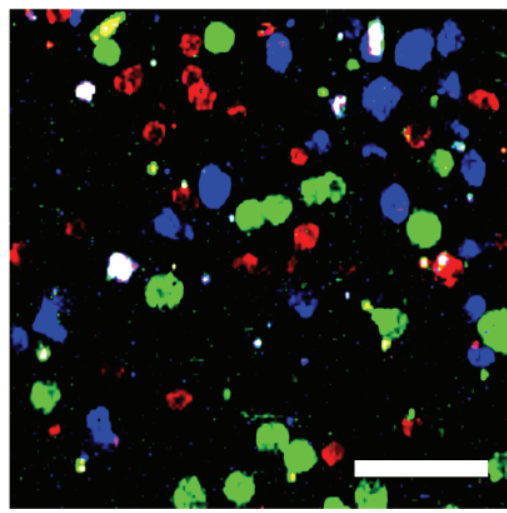

(c)

Figure 16 Multi-color Raman imaging with isotopically modified SWNTs. (a) Schematic illustration of SWNTs with three different isotope compositions $\left({ }^{13} \mathrm{C}\right.$-SWNT, ${ }^{12} \mathrm{C} 12 /{ }^{13} \mathrm{C}$-SWNT, ${ }^{12} \mathrm{C}$-SWNT) conjugated with different targeting ligands. (b) Solution phase Raman spectra of the three SWNT conjugates under $785 \mathrm{~nm}$ laser excitation. Different G-band peak positions were observed. (c) A deconvoluted confocal Raman spectroscopy image of a mixture of three cell lines with different receptor expressions incubated with the three-color SWNT mixture. Scale bar = $100 \mu \mathrm{m}$. Copyright 2008 American Chemical Society [127] 
systems In vitro and in vivo. Thus, SWNTs are novel Raman tags which show promise for multiplexed biological detection and imaging.

\subsection{SWNTs for in vivo animal imaging}

SWNT-based biomedical imaging has also been conducted in animal models. The first ever imaging of nanotubes inside a living animal was achieved by the Weisman group in 2007 [94]. In this work, Drosophila larvae were fed by food containing SWNTs and imaged by NIR fluorescence microscopy. The biodistribution of SWNTs in live larvae was monitored by the nanotube fluorescence signals. Recently, the Gambhir group successfully used RGDconjugated PEGylated SWNTs provided by us as Raman probes for in vivo tumor imaging in live mice (Fig. 17) [153, 154]. Intravenous injection of targeted SWNTs to living mice bearing a tumor xenograft, showed strong SWNT Raman signals in the tumor, while little signal was observed in the tumor after injection of non-targeted SWNTs. This is the first success of in vivo tumor imaging via carbon nanotube labels.

SWNTs have strong optical absorption in the visible and NIR range. We and Chakravarty et al. have shown that SWNTs can be utilized as photothermal therapeutic agents to kill cancer cells $[20,128]$. NIR laser irradiation was used in both cases to generate heat, causing destruction of cancer cells with specific SWNT internalization. Beside its potential applications in therapy, the high optical absorption of SWNTs can also be utilized in photoacoustic imaging. Photoacoustic imaging, in which sounds are generated as a result of local heating by the absorption of laser light, has higher spatial resolution than traditional ultrasound, and deeper tissue penetration than fluorescence imaging [155]. de la Zerda et al. used our RGD-conjugated SWNTs as the contrast agent for photoacoustic molecular imaging of cancer in a mouse tumor model (Fig. 17) [22]. This work opens up new opportunities for in vivo biological imaging with SWNTs.

\section{Summary and perspective}

In this article, we have comprehensively reviewed the current research regarding the use of carbon nanotubes for biomedical applications. Various covalent and noncovalent chemistries have been developed to functionalize CNTs for biomedical
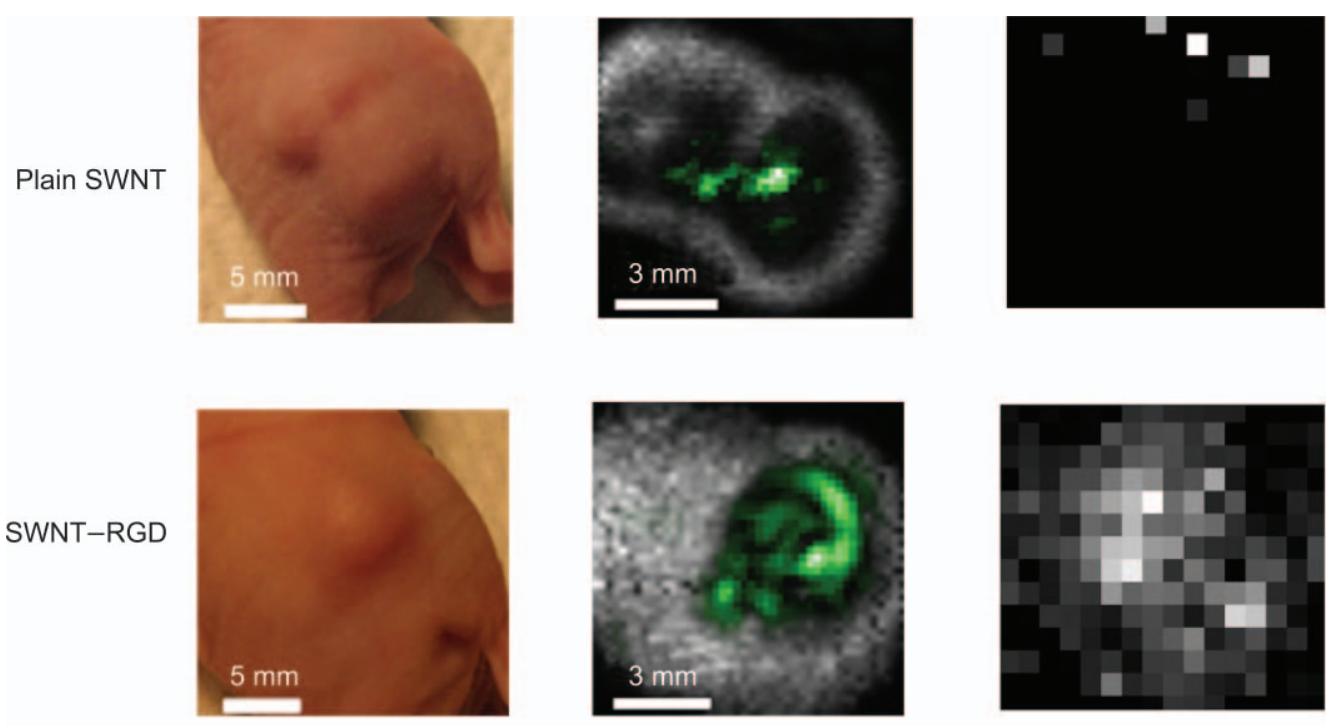

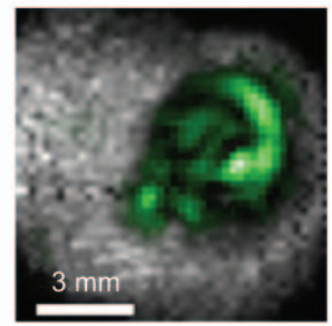

Photoacoustic in vivo imaging

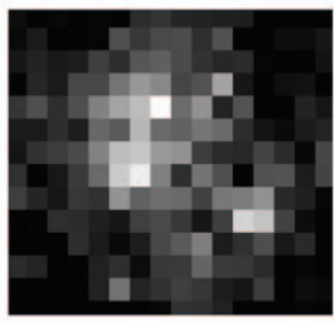

Raman in vivo imaging

Figure 17 In vivo tumor imaging with SWNTs. In vivo photoacoustic (strong light absorption of SWNTs generates an acoustic signal) and Raman images of U87MG tumors in live mice injected with plain SWNT or RGD-conjugated SWNT. Strong tumor contrast induced by SWNT-RGD was observed in both imaging techniques. Copyright 2008 American Chemical Society [154], 2008 Nature Publishing Group [22], and 2008 the National Academy of Sciences [153] 
research. Relying on their electric or optical properties, functionalized CNTs have been used for ultrasensitive detection of biological species. Surveying the literatures, we clarify that In vitro and in vivo toxicities of CNTs are highly dependent on CNT functionalization. Appropriately functionalized CNTs with biocompatible coatings are stable in biological solutions, and nontoxic In vitro to cells and in vivo to mice at the tested doses. Various reports have shown that CNTs are able to shuttle biological molecules including small drug molecules and biomacromolecules including proteins, plasmid DNA, and siRNA into cells In vitro via an endocytosis pathway. In vivo behaviors, including blood circulation, biodistribution, and long term fate of CNTs, have been studied in the past two years, showing dominant uptake of CNTs in RES organs, similar to most nanomaterials tested in vivo. CNTs are able to target tumors by both passive targeting relying on the EPR effect and active targeting guided by targeting ligands, showing promise for in vivo cancer treatment. Moreover, SWNTs exhibit unparalleled intrinsic optical properties and have been used for biological imaging In vitro and in vivo.

Surface functionalization chemistry is the most essential and fundamental factor as far as biomedical applications of CNTs are concerned. Highly hydrophilic coatings, such as long and branched PEG on CNTs, impart "inertness" in biological environments, minimizing the toxicity of CNTs and reducing NSB to biological species, such as serum proteins and cell surface proteins. Minimal NSB is critical since it leads to enhanced detection sensitivity in CNT-based biosenors and imaging probes. Decreased NSB reduces the non-specific endocytosis of CNTs, which favors targeted drug delivery to specific cell types. Similarly, the in vivo behaviors of CNTs are highly dependent on their surface coating. Prolonged blood circulation and reduced RES uptake can be achieved by using CNTs with highly hydrophilic coatings. Further efforts are required to optimize the surface chemistry of SWNTs, to further enhance biocompatibility. With improved surface coating, further improvements in biological sensing and imaging, better tumor targeting attributed to prolonged blood circulation and reduced RES uptake, and accelerated excretion may be realized. By minimizing the non-specific protein binding of nanotubes via improved surface functionalization, complement activation may also be reduced for SWNTs.

CNTs, especially SWNTs are highly promising in biomedicine for several reasons. CNTs are composed purely of carbon, while many inorganic nanomaterials (e.g., quantum dots) contain more hazardous elements, such as heavy metals. The distinctive 1-D structure and tunable length of CNTs provide an ideal platform to investigate size and shape effects in vivo. Lastly, unlike conventional organic drug carriers, the intrinsic physical properties of SWNTs including resonance Raman scattering, photoluminescence, and strong NIR optical absorption can provide valuable means of tracking, detecting, and imaging. Taken together, CNTs may serve as a unique platform for potential multimodality cancer therapy and imaging.

Although numerous encouraging results using CNTs in biomedicine have been published in the past several years, much more work is still needed before CNTs can enter the clinic. The most important issue to be addressed is still the concern of longterm toxicity. Although we have shown that wellfunctionalized carbon nanotubes are not toxic In vitro to cells and in vivo to mice at our tested doses, further systematic investigations using different animal models on larger scales with various doses are required. Special attention should be paid to CNTs with surface functionalization optimized for such applications, with greater chances of minimizing toxic side effects.

Although we have succeeded in using carbon nanotubes for In vitro siRNA delivery, in vivo delivery of this type of biological macromolecules remains a challenge. A paradox exists because of the need for high In vitro cellular uptake and the requirement of favorable in vivo behavior such as long blood circulation and low RES uptake of SWNTs. The former suggests reduced PEGylation of nanotubes, while the latter requires dense biocompatible surface coatings. Conjugation of targeting ligands on appropriately coated SWNTs may help to solve this problem, allowing enhanced cellular uptake 
via receptor mediated endocytosis, without loss of optimal SWNT in vivo characteristics. Further development of suitable bioconjugation chemistry on nanotubes may create versatile SWNT-based bioconjugates for actively targeted in vivo drug and gene delivery.

Although not specifically discussed in this review, the fabrication of CNTs may also play an important role in their future biomedical applications. Most of the CNT samples used in the published biomedical studies are heterogeneous mixtures of nanotubes with different lengths, diameters, and chiralities. The lengths of CNTs may affect In vitro cellular uptake as well as in vivo pharmacokinetics of nanotubes. It is thus important to obtain and test nanotube samples with narrow length distributions. A density columnbased length separation method has been developed in our group [156]. Further studies will uncover potential length dependent effects on the behavior of CNTs in biological systems. The electronic structures of SWNTs are determined by their chiralities (Fig. 1). Achieving SWNTs with single diameter and chirality may bring a revolution to the semiconductor industry and has been one of the ultimate goals of nanotube research for a decade. Progress has been made by selective synthesis of SWNTs under special conditions [157], removal of SWNTs with undesired diameters by etching [102], and chirality separation based on chromatography $[73,74]$. Different semiconducting SWNTs with single chirality compositions can serve as different colors in NIR photoluminescence imaging (Fig. 1). One the other hand, Raman scattering of SWNTs with single chirality will be largely enhanced because all nanotubes can be in resonance with a selected excitation wavelength. The diameterdependent Raman RBM band of SWNTs may also be utilized in multi-color Raman imaging [25, 158]. CNT samples with homogenous length, diameter, and chirality distributions are the ideal candidates for further studies in biomedicine.

Lastly, biomedical imaging, based on the inherent physical properties of SWNTs, may be combined with drug delivery for multimodality cancer diagnosis and therapy. Phototherapy relying on the strong NIR light absorption ability of SWNTs may be conducted simultaneously, along with chemotherapy delivered by SWNTs, to enhance treatment efficacy in vivo. Despite challenges on the way towards the clinic, carbon nanotubes exhibit great potential for biomedicine, and may bring unprecedented opportunities for the future of cancer diagnosis and therapy.

\section{References}

[1] Whitesides, G. M. The "right" size in nanobiotechnology. Nat. Biotech. 2003, 21, 1161-1165.

[2] Lowe, C. R. Nanobiotechnology: The fabrication and applications of chemical and biological nanostructures. Curr. Opin. Chem. Biol. 2000, 10, 428-434.

[3] Wang, L.; Zhao, W.; Tan, W. Bioconjugated silica nanoparticles: Development and applications. Nano Res. 2008, 1, 99-115.

[4] lijima, S. Helical microtubules of graphitic carbon. Nature 1991, 354, 56-58.

[5] Dai, H. Carbon nanotubes: Synthesis, integration, and properties. Acc. Chem. Res. 2002, 35, 1035-1044.

[6] Dresselhaus, M.; Dai, H. (eds.) MRS 2004 Carbon Nanotube Special Issue, Vol. 29, 2004.

[7] Golberg, D.; Costa, P. M. F. J.; Mitome, M.; Bando, Y. Nanotubes in a gradient electric field as revealed by STM-TEM technique. Nano Res. 2008, 1, 166-175.

[8] Zhou, W.; Rutherglen, C.; Burke, P. Wafer scale synthesis of dense aligned arrays of single-walled carbon nanotubes. Nano Res. 2008, 1, 158-165.

[9] Ago, H.; Petritsch, K.; Shaffer, M. S. P.; Windle, A. H.; Friend, R. H. Composites of carbon nanotubes and conjugated polymers for photovoltaic devices. Adv. Mater. 1999, 11, 1281-1285.

[10] Javey, A.; Guo, J.; Wang, Q.; Lundstrom, M.; Dai, H. J. Ballistic carbon nanotube field-effect transistors. Nature 2003, 424, 654-657

[11] Cao, Q.; Rogers, J. A. Random networks and aligned arrays of single-walled carbon nanotubes for electronic device applications. Nano Res. 2008, 1, 259-272.

[12] Fan, S. S.; Chapline, M. G.; Franklin, N. R.; Tombler, T. W.; Cassell, A. M.; Dai, H. J. Self-oriented regular arrays of carbon nanotubes and their field emission properties. Science 1999, 283, 512-514.

[13] Dillon, A. C.; Jones, K. M.; Bekkedahl, T. A.; Kiang, C. H.; Bethune, D. S.; Heben, M. J. Storage of hydrogen in single-walled carbon nanotubes. Nature 1997, 386, 
377-379.

[14] Chen, R. J.; Bangsaruntip, S.; Drouvalakis, K. A.; Kam, N. W. S.; Shim, M.; Li, Y. M.; Kim, W.; Utz, P. J; Dai, H. J. Noncovalent functionalization of carbon nanotubes for highly specific electronic biosensors. Proc. Nat. Acad. Sci. USA 2003, 100, 4984-4989.

[15] Kam, N. W. S.; Jessop, T. C.; Wender, P. A.; Dai, H. J. Nanotube molecular transporters: Internalization of carbon nanotube-protein conjugates into mammalian cells. J. Am. Chem. Soc. 2004, 126, 6850-6851.

[16] Bianco, A.; Kostarelos, K.; Partidos, C. D.; Prato, M. Biomedical applications of functionalised carbon nanotubes. Chem. Commun. 2005, 571-577.

[17] Cherukuri, P.; Bachilo, S. M.; Litovsky, S. H; Weisman, R. B. Near-infrared fluorescence microscopy of single-walled carbon nanotubes in phagocytic cells. J. Am. Chem. Soc. 2004, 126, 15638-15639.

[18] Liu, Z.; Sun, X.; Nakayama, N.; Dai, H. Supramolecular chemistry on water-soluble carbon nanotubes for drug loading and delivery. ACS Nano 2007, 1, 50-56.

[19] Tans, S. J.; Devoret, M. H.; Dai, H. J.; Thess, A.; Smalley, R. E.; Geerligs, L. J.; Dekker, C. Individual single-wall carbon nanotubes as quantum wires. Nature 1997, 386, 474477.

[20] Kam, N. W. S.; O'Connell, M.; Wisdom, J. A.; Dai, $\mathrm{H}$. Carbon nanotubes as multifunctional biological transporters and near-infrared agents for selective cancer cell destruction. Proc. Natl. Acad. Sci. USA 2005, 102, 11600-11605.

[21] Chakravarty, P.; Marches, R.; Zimmerman, N. S.; Swafford, A. D. E.; Bajaj, P.; Musselman, I. H.; Pantano, P.; Draper, R. K.; Vitetta, E. S. Thermal ablation of tumor cells with anti body-functionalized single-walled carbon nanotubes. Proc. Natl. Acad. Sci. U S A 2008, 105, 8697 -8702 .

[22] Zerda, A. d. I.; Zavaleta, C.; Keren, S.; Vaithilingam, S.; Bodapati, S.; Liu, Z.; Levi, J.; Ma, T. -J.; Oralkan, O.; Cheng, Z., et al. Photoacoustic molecular imaging in living mice utilizing targeted carbon nanotubes. Nat. Nanotech. 2008, 3, 557- 562.

[23] O'Connell, M. J.; Bachilo, S. M.; Huffman, C. B.; Moore, V. C.; Strano, M. S.; Haroz, E. H.; Rialon, K. L.; Boul, P. J.; Noon, W. H.; Kittrell, C., et al. Band gap fluorescence from individual single-walled carbon nanotubes. Science 2002, 297, 593-596.

[24] Welsher, K.; Liu, Z.; D, D.; Dai, H. Selective probing and imaging of cells with single walled carbon nanotubes as near-infrared fluorescent molecules. Nano Lett. 2008, 8, 586-590.

[25] Rao, A. M.; Richter, E.; Bandow, S.; Chase, B.; Eklund, P. C.; Williams, K. A.; Fang, S.; Subbaswamy, K. R.; Menon, M.; Thess, A., et al. Diameter-selective Raman scattering from vibrational modes in carbon nanotubes. Science 1997, 275, 187-191.

[26] Heller, D. A.; Baik, S.; Eurell, T. E.; Strano, M. S. Singlewalled carbon nanotube spectroscopy in live cells: Towards long-term labels and optical sensors. Adv. Mater. 2005, 17, 2793-2799.

[27] Pantarotto, D.; Singh, R.; McCarthy, D.; Erhardt, M.; Briand, J. P.; Prato, M.; Kostarelos, K; Bianco, A Functionalized carbon nanotubes for plasmid DNA gene delivery. Angew. Chem. Int. Ed. 2004, 43, 5242-5246.

[28] Liu, Y.; Wu, D. C.; Zhang, W. D.; Jiang, X.; He, C. B.; Chung, T. S.; Goh, S. H.; Leong, K. W. Polyethyleniminegrafted multiwalled carbon nanotubes for secure noncovalent immobilization and efficient delivery of DNA. Angew. Chem. Int. Ed. 2005, 44, 4782-4785.

[29] Singh, R.; Pantarotto, D.; McCarthy, D.; Chaloin, O.; Hoebeke, J.; Partidos, C. D.; Briand, J. P.; Prato, M.; Bianco, A.; Kostarelos, K. Binding and condensation of plasmid DNA onto functionalized carbon nanotubes: Toward the construction of nanotube-based gene delivery vectors. J. Am. Chem. Soc. 2005, 127, 43884396.

[30] Gao, L. Z.; Nie, L.; Wang, T. H.; Qin, Y. J.; Guo, Z. X.; Yang, D. L; Yan, X. Y. Carbon nanotube delivery of the GFP gene into mammalian cells. ChemBioChem 2006, 7, 239-242.

[31] Tang, X. W.; Bansaruntip, S.; Nakayama, N.; Yenilmez, E.; Chang, Y. L.; Wang, Q. Carbon nanotube DNA sensor and sensing mechanism. Nano Lett. 2006, 6, 1632 1636.

[32] Chen, Z.; Tabakman, S. M.; Goodwin, A. P.; Kattah, M. G.; Daranciang, D.; Wang, X.; Zhang, G.; Li, X.; Liu, Z.; Utz, P. J., et al. Protein microarrays with carbon nanotubes as multi-color Raman labels. Nat. Biotech. 2008, in press, DOI: $10.1038 / \mathrm{nbt}$.150.

[33] Kam, N. W. S.; Dai, H. Carbon nanotubes as intracellular protein transporters: Generality and biological functionality. J. Am. Chem. Soc. 2005, 127, 6021-6026.

[34] Kam, N. W. S.; Liu, Z. A.; Dai, H. J. Carbon nanotubes as intracellular transporters for proteins and DNA: An 
investigation of the uptake mechanism and pathway. Angew. Chem. Int. Ed. 2006, 45, 577-581.

[35] Kam, N. W. S.; Liu, Z.; Dai, H. Functionalization of carbon nanotubes via cleavable disulfide bonds for efficient intracellular delivery of siRNA and potent gene silencing. J. Am. Chem. Soc. 2005, 127, 12492-12493.

[36] Pantarotto, D.; Briand, J. P.; Prato, M.; Bianco, A. Translocation of bioactive peptides across cell membranes by carbon nanotubes. Chem. Commun. 2004, 16-17.

[37] Liu, Z.; Chen, K.; Davis, C.; Sherlock, S.; Cao, Q.; Chen, X.; Dai, H. Drug delivery with carbon nanotubes for in vivo cancer treatment. Cancer Res. 2008, 68, 66526660.

[38] Cui, D. X.; Tian, F. R.; Ozkan, C. S.; Wang, M.; Gao, H. J. Effect of single wall carbon nanotubes on human HEK293 cells. Toxicol. Lett. 2005, 155, 73-85.

[39] Lam, C. W.; James, J. T.; McCluskey, R.; Hunter, R. L. Pulmonary toxicity of single-wall carbon nanotubes in mice 7 and 90 days after intratracheal instillation. Toxicol. Lett. 2004, 77, 126-134.

[40] Warheit, D. B.; Laurence, B. R.; Reed, K. L.; Roach, D. H.; Reynolds, G. A. M.; Webb, T. R. Comparative pulmonary toxicity assessment of single-wall carbon nanotubes in rats. Toxicol. Lett. 2004, 77, 117-125.

[41] Ding, L. H.; Stilwell, J.; Zhang, T. T.; Elboudwarej, O.; Jiang, H. J.; Selegue, J. P.; Cooke, P. A.; Gray, J. W.; Chen, F. Q. F. Molecular characterization of the cytotoxic mechanism of multiwall carbon nanotubes and nanoonions on human skin fibroblast. Nano Lett. 2005, 5, 2448-2464.

[42] Bottini, M.; Bruckner, S.; Nika, K.; Bottini, N.; Bellucci, S.; Magrini, A.; Bergamaschi, A.; Mustelin, T. Multi-walled carbon nanotubes induce $T$ lymphocyte apoptosis. Toxicol. Lett. 2006, 160, 121-126.

[43] Poland, C. A.; Duffin, R.; Kinloch, I.; Maynard, A.; Wallace, W. A. H.; Seaton, A.; Stone, V.; Brown, S.; MacNee, W.; Donaldson, K. Carbon nanotubes introduced into the abdominal cavity of mice show asbestos-like pathogenicity in a pilot study. Nat. Nanotech. 2008, 3, 423-428.

[44] Liu, Z.; Cai, W. B.; He, L. N.; Nakayama, N.; Chen, K.; Sun, X. M.; Chen, X. Y.; Dai, H. J. In vivo biodistribution and highly efficient tumour targeting of carbon nanotubes in mice. Nat. Nanotech. 2007, 2, 47-52.

[45] Liu, Z.; Davis, C.; Cai, W.; He, L.; Chen, X.; Dai, H. Circulation and long-term fate of functionalized, biocompatible single-walled carbon nanotubes in mice probed by Raman spectroscopy. Proc. Natl. Acad. Sci. USA 2008, 105, 1410-1415.

[46] Singh, R.; Pantarotto, D.; Lacerda, L.; Pastorin, G.; Klumpp, C.; Prato, M.; Bianco, A.; Kostarelos, K. Tissue biodistribution and blood clearance rates of intravenously administered carbon nanotube radiotracers. Proc. Nat. Acad. Sci. USA 2006, 103, 3357-3362.

[47] Lacerda, L.; Soundararajan, A.; Singh, R.; Pastorin, G.; Al-Jamal, K. T.; Turton, J.; Frederik, P.; Herrero, M. A.; Bao, S. L. A.; Emfietzoglou, D., et al. Dynamic imaging of functionalized multi-walled carbon nanotube systemic circulation and urinary excretion. Adv. Mater. 2008, 20, 225-230.

[48] Yang, S. T.; Guo, W.; Lin, Y.; Deng, X. Y.; Wang, H. F.; Sun, H. F.; Liu, Y. F.; Wang, X.; Wang, W.; Chen, M., et al. Biodistribution of pristine single-walled carbon nanotubes in vivo. J. Phys. Chem. C 2007, 111, 1776117764.

[49] Deng, X. Y.; Yang, S. T.; Nie, H. Y.; Wang, H. F.; Liu, Y. F. A generally adoptable radiotracing method for tracking carbon nanotubes in animals. Nanotechnology 2008, 19, 075101

[50] Cherukuri, P.; Gannon, C. J.; Leeuw, T. K.; Schmidt, H. K.; Smalley, R. E.; Curley, S. A.; Weisman, R. B. Mammalian pharmacokinetics of carbon nanotubes using intrinsic near-infrared fluorescence. Proc. Natl. Acad. Sci. USA 2006, 103, 18882-18886.

[51] Liu, Z.; Winters, M.; Holodniy, M.; Dai, H. J. siRNA delivery into human $T$ cells and primary cells with carbonnanotube transporters. Angew. Chem. Int. Ed. 2007, 46, 2023-2027.

[52] Wu, W.; Wieckowski, S.; Pastorin, G.; Benincasa, M.; Klumpp, C.; Briand, J. P.; Gennaro, R.; Prato, M.; Bianco, A. Targeted delivery of amphotericin $B$ to cells by using functionalized carbon nanotubes. Angew. Chem. Int. Ed. 2005, 44, 6358-6362.

[53] Dumortier, H.; Lacotte, S.; Pastorin, G.; Marega, R.; Wu, W.; Bonifazi, D.; Briand, J. P.; Prato, M.; Muller, S.; Bianco, A. Functionalized carbon nanotubes are noncytotoxic and preserve the functionality of primary immune cells. Nano Lett. 2006, 6, 1522-1528.

[54] Chen, X.; Lee, G. S.; Zettl, A.; Bertozzi, C. R. Biomimetic engineering of carbon nanotubes by using cell surface mucin mimics. Angew. Chem. Int. Ed. 2004, 43, 61116116. 
[55] Chen, X.; Tam, U. C.; Czlapinski, J. L.; Lee, G. S.; Rabuka, D.; Zettl, A.; Bertozzi, C. R. Interfacing carbon nanotubes with living cells. J. Am. Chem. Soc. 2006, 128, 62926293.

[56] Chin, S. F.; Baughman, R. H.; Dalton, A. B.; Dieckmann, G. R.; Draper, R. K.; Mikoryak, C.; Musselman, I. H.; Poenitzsch, V. Z.; Xie, H.; Pantano, P. Amphiphilic helical peptide enhances the uptake of single-walled carbon nanotubes by living cells. Exper. Biol. Med. 2007, 232, 1236-1244.

[57] Yehia, H. N.; Draper, R. K.; Mikoryak, C.; Walker, E. K.; Bajaj, P.; Musselman, I. H.; Daigrepont, M. C.; Dieckmann, G. R.; Pantano, P. Single-walled carbon nanotube interactions with HeLa cells. J. Nanobiotech. 2007, 5, 8.

[58] Schipper, M. L.; Nakayama-Ratchford, N.; Davis, C. R.; Kam, N. W. S.; Chu, P.; Liu, Z.; Sun, X.; Dai, H.; Gambhir, S. S. A pilot toxicology study of single-walled carbon nanotubes in a small sample of mice. Nat. Nanotech.

2008, 3, 216-221.

[59] Niyogi, S.; Hamon, M. A.; Hu, H.; Zhao, B.; Bhowmik, P.; Sen, R.; Itkis, M. E.; Haddon, R. C. Chemistry of singlewalled carbon nanotubes. Acc. Chem. Res. 2002, 35, 1105-1113.

[60] Rosca, I. D.; Watari, F.; Uo, M.; Akaska, T. Oxidation of multiwalled carbon nanotubes by nitric acid. Carbon 2005, 43, 3124-3131.

[61] Zeng, L.; Alemany, L. B.; Edwards, C. L.; Barron, A. R. Demonstration of covalent sidewall functionalization of single wall carbon nanotubes by NMR spectroscopy: Side chain length dependence on the observation of the sidewall sp ${ }^{3}$ carbons. Nano Res. 2008, 1, 72-88.

[62] Zhao, B.; Hu, H.; Yu, A. P.; Perea, D.; Haddon, R. C. Synthesis and characterization of water soluble singlewalled carbon nanotube graft copolymers. J. Am. Chem. Soc. 2005, 127, 8197-8203.

[63] Lee, K. M.; Li, L. C.; Dai, L. M. Asymmetric endfunctionalization of multi-walled carbon nanotubes. J. Am. Chem. Soc. 2005, 127, 4122-4123.

[64] Moghaddam, M. J.; Taylor, S.; Gao, M.; Huang, S. M.; Dai, L. M.; McCall, M. J. Highly efficient binding of DNA on the sidewalls and tips of carbon nanotubes using photochemistry. Nano Lett. 2004, 4, 89-93.

[65] Coleman, K. S.; Bailey, S. R.; Fogden, S.; Green, M. L. H. Functionalization of single-walled carbon nanotubes via the Bingel reaction. J. Am. Chem. Soc. 2003, 125, 8722
$-8723$.

[66] Umeyama, T.; Tezuka, N.; Fujita, M.; Matano, Y.; Takeda, N.; Murakoshi, K.; Yoshida, K.; Isoda, S.; Imahori, H. Retention of intrinsic electronic properties of soluble single-walled carbon nanotubes after a significant degree of sidewall functionalization by the Bingel reaction. J. Phys. Chem. C 2007, 111, 9734-9741.

[67] Georgakilas, V.; Kordatos, K.; Prato, M.; Guldi, D. M.; Holzinger, M.; Hirsch, A. Organic functionalization of carbon nanotubes. J. Am. Chem. Soc. 2002, 124, 760761.

[68] Tagmatarchis, N.; Prato, M. Functionalization of carbon nanotubes via 1,3-dipolar cycloadditions. J. Mater. Chem. 2004, 14, 437-439.

[69] Pastorin, G.; Wu, W.; Wieckowski, S.; Briand, J. P.; Kostarelos, K.; Prato, M.; Bianco, A. Double functionalisation of carbon nanotubes for multimodal drug delivery. Chem. Commun. 2006, 1182-1184.

[70] Chen, R. J.; Zhang, Y. G.; Wang, D. W.; Dai, H. J. Noncovalent sidewall functionalization of single-walled carbon nanotubes for protein immobilization. J. Am Chem. Soc. 2001, 123, 3838-3839.

[71] Chen, J.; Liu, H. Y.; Weimer, W. A.; Halls, M. D.; Waldeck, D. H.; Walker, G. C. Noncovalent engineering of carbon nanotube surfaces by rigid, functional conjugated polymers. J. Am. Chem. Soc. 2002, 124, 9034-9035.

[72] Wu, P.; Chen, X.; Hu, N.; Tam, U. C.; Blixt, O.; Zettl, A.; Bertozzi, C. R. Biocompatible carbon nanotubes generated by functionalization with glycodendrimers. Angew. Chem. Int. Ed. 2008, 47, 5022-5025.

[73] Zheng, M.; Jagota, A.; Semke, E. D.; Diner, B. A.; Mclean, R. S.; Lustig, S. R.; Richardson, R. E.; Tassi, N. G. DNAassisted dispersion and separation of carbon nanotubes. Nat. Mater. 2003, 2, 338-342.

[74] Tu, X.; Zheng, M. A DNA-based approach to the carbon nanotube sorting problem. Nano Res. 2008, 1, 185-194.

[75] Moon, H. K.; Chang, C. I.; Lee, D. -K.; Choi, H. C. Effect of nucleases on the cellular internalization of fluorescent labeled DNA-functionalized single-walled carbon nanotubes. Nano Res. 2008, 1, 351-360.

[76] Nakayama-Ratchford, N.; Bangsaruntip, S.; Sun, X. M.; Welsher, K.; Dai, H. J. Noncovalent functionalization of carbon nanotubes by fluorescein-polyethylene glycol: Supramolecular conjugates with $\mathrm{pH}$-dependent absorbance and fluorescence. J. Am. Chem. Soc. 2007, 129, 2448-2449. 
[77] Guldi, D. M.; Taieb, H.; Rahman, G. M. A.; Tagmatarchis, N.; Prato, M. Novel photoactive single-walled carbon nanotube-porphyrin polymer wraps: Efficient and longlived intracomplex charge separation. Adv. Mater. 2005, 17, 871-875.

[78] Richard, C.; Balavoine, F.; Schultz, P.; Ebbesen, T. W.;Mioskowski, C. Supramolecular self-assembly of lipid derivatives on carbon nanotubes. Science 2003, 300, $775-778$.

[79] Wang, H.; Zhou, W.; Ho, D. L.; Winey, K. I.; Fischer, J. E.; Glinka, C. J.; Hobbie, E. K. Dispersing single-walled carbon nanotubes with surfactants: A small angle neutron scattering study. Nano Lett. 2004, 4, 17891793.

[80] Wong, S. S.; Joselevich, E.; Woolley, A. T.; Cheung, C. L.; Lieber, C. M. Covalently functionalized nanotubes as nanometre-sized probes in chemistry and biology. Nature 1998, 394, 52-55.

[81] Lin, Y.; Taylor, S.; Li, H. P.; Fernando, K. A. S.; Qu, L. W.; Wang, W.; Gu, L. R.; Zhou, B.; Sun, Y. P. Advances toward bioapplications of carbon nanotubes. J. Mater. Chem. 2004, 14, 527-541.

[82] Balavoine, F.; Schultz, P.; Richard, C.; Mallouh, V.; Ebbesen, T. W.; Mioskowski, C. Helical crystallization of proteins on carbon nanotubes: A first step towards the development of new biosensors. Angew. Chem. Int. Ed. 1999, 38, 1912-1915.

[83] Shim, M.; Kam, N.; Chen, R.; Li, Y.; Dai, H. Functionalization of carbon nanotubes for biocompatibility and biom-olecular recognition. Nano Lett. 2002, 2, 285288.

[84] Azamian, B. R.; Davis, J. J.; Coleman, K. S.; Bagshaw, C. B.; Green, M. L. H. Bioelectrochemical single-walled carbon nanotubes. J. Am. Chem. Soc. 2002, 124, 12664-12665.

[85] Erlanger, B. F.; Chen, B. X.; Zhu, M.; Brus, L. Binding of an anti-fullerene $\lg G$ monoclonal antibody to single wall carbon nanotubes. Nano Lett. 2001, 1, 465-467.

[86] Wang, S. Q.; Humphreys, E. S.; Chung, S. Y.; Delduco, D. F.; Lustig, S. R.; Wang, H.; Parker, K. N.; Rizzo, N. W.; Subramoney, S.; Chiang, Y. M., et al. Peptides with selective affinity for carbon nanotubes. Nat. Mater. 2003, 2, 196-200.

[87] Chen, R. J.; Choi, H. C.; Bangsaruntip, S.; Yenilmez, E.; Tang, X. W.; Wang, Q.; Chang, Y. L.; Dai, H. J. An investigation of the mechanisms of electronic sensing of protein adsorption on carbon nanotube devices. J. Am. Chem. Soc. 2004, 126, 1563-1568.

[88] Chandler, D. Interfaces and the driving force of hydrophobic assembly. Nature 2005, 437, 640-647.

[89] Karajanagi, S. S.; Vertegel, A. A.; Kane, R. S.; Dordick, J. S. Structure and function of enzymes adsorbed onto singlewalled carbon nanotubes. Langmuir 2004, 20, 1159411599.

[90] Kong, J.; Franklin, N. R.; Zhou, C. W.; Chapline, M. G.; Peng, S.; Cho, K. J. Dai, H. J. Nanotube molecular wires as chemical sensors. Science 2000, 287, 622-625.

[91] Byon, H. R.; Choi, H. C. Network single-walled carbon nanotube-field effect transistors (SWNT-FETs) with increased Schottky contact area for highly sensitive biosensor applications. J. Am. Chem. Soc. 2006, 128, 2188-2189.

[92] Kim, S. N.; Rusling, J. F.; Papadimitrakopoulos, F. Carbon nanotubes for electronic and electrochemical detection of biomolecules. Adv. Mater. 2007, 19, 3214-3228.

[93] Wang, J. Carbon-nanotube-based electrochemical biosensors: A review. Electroanalysis 2005, 17, 7-14.

[94] Leeuw, T. K.; Reith, R. M.; Simonette, R. A.; Harden, M. E.; Cherukuri, P.; Tsyboulski, D. A.; Beckingham, K. M.; Weisman, R. B. Single-walled carbon nanotubes in the intact organism: Near-IR imaging and biocompatibility studies in Drosophila. Nano Lett. 2007, 7, 2650-2654.

[95] Jin, H.; Heller, D. A.; Strano, M. S. Single-particle tracking of endocytosis and exocytosis of single-walled carbon nanotubes in NIH-3T3 cells. Nano Lett. 2008, 8, 15771585.

[96] Barone, P. W.; Parker, R. S.; Strano, M. S. In vivo fluorescence detection of glucose using a single-walled carbon nanotube optical sensor: Design, fluorophore properties, advantages, and disadvantages. Anal. Chem. 2005, 77, 7556-7562.

[97] Jeng, E. S.; Moll, A. E.; Roy, A. C.; Gastala, J. B.; Strano, M. S. Detection of DNA hybridization using the nearinfrared band-gap fluorescence of single-walled carbon nanotubes. Nano Lett. 2006, 6, 371-375.

[98] Barone, P. W.; Baik, S.; Heller, D. A.; Strano, M. S. Nearinfrared optical sensors based on single-walled carbon nanotubes. Nat. Mater. 2004, 4, 86-92.

[99] Satishkumar, B. C.; Brown, L. O.; Gao, Y.; Wang, C. C.; Wang, H. L.; Doorn, S. K. Reversible fluorescence quenching in carbon nanotubes for biomolecular sensing. Nat. Nanotech. 2007, 2, 560-564. 
[100] Yang, R. H.; Jin, J. Y.; Chen, Y.; Shao, N.; Kang, H. Z.; Xiao, Z.; Tang, Z. W.; Wu, Y. R.; Zhu, Z.; Tan, W. H. Carbon nanotube-quenched fluorescent oligonucleotides: Probes that fluoresce upon hybridization. J. Am. Chem. Soc. 2008, 130, 83518358.

[101] Crochet, J.; Clemens, M.; Hertel, T. Quantum yield heterogeneities of aqueous single-wall carbon nanotube suspensions. J. Am. Chem. Soc. 2007, 129, 8058-8059.

[102] Zhang, G. Y.; Qi, P. F.; Wang, X. R.; Lu, Y. R.; Li, X. L.; Tu, R.; Bangsaruntip, S.; Mann, D.; Zhang, L.; Dai, H. J. Selective etching of metallic carbon nanotubes by gasphase reaction. Science 2006, 314, 974-977.

[103] MacBeath, G.; Schreiber, S. L. Printing proteins as microarrays for high-throughput function determination. Science 2000, 289, 1760-1763.

[104] Bailey, R. C.; Kwong, G. A.; Radu, C. G.; Witte, O. N.; Heath, J. R. DNA-encoded antibody libraries: A unified platform for multiplexed cell sorting and detection of genes and proteins. J. Am. Chem. Soc. 2007, 129, 1959-1967.

[105] Robinson, W. H.; DiGennaro, C.; Hueber, W.; Haab, B. B.; Kamachi, M.; Dean, E. J.; Fournel, S.; Fong, D.; Genovese, M. C.; de Vegvar, H. E., et al. Autoantigen microarrays for multiplex characterization of autoantibody responses. Nat. Med. 2002, 8, 295-301.

[106] Nie, S.; Emory, S. R. Probing single molecules and single nanoparticles by surface-enhanced Raman scattering. Science 1997, 275, 1102-1106.

[107] Jeanmaire, D. L.; Vanduyne, R. P. Surface Raman Spectroelectrochemistry.1. Heterocyclic, aromatic, and aliphatic amines adsorbed on anodized silver electrode. J. Electroanal. Chem. 1977, 84, 1-20.

[108] Espina, V.; Woodhouse, E. C.; Wulfkuhle, J.; Asmussen, H. D.; Petricoin, E. F.; Liotta, L. A. Protein microarray detection strategies: Focus on direct detection technologies. J. Immunol. Methods 2004, 290, 121133.

[109] Prakash, A.; Mallick, P.; Whiteaker, J.; Zhang, H.; Paulovich, A.; Flory, M.; Lee, H.; Aebersold, R.; Schwikowski, B. Signal maps for mass spectrometrybased comparative proteomics. Mol. Cell. Proteomics 2006, 5, 423-432.

[110] Shvedova, A. A.; Kisin, E. R.; Mercer, R.; Murray, A. R.; Johnson, V. J.; Potapovich, A. I.; Tyurina, Y. Y.; Gorelik,
O.; Arepalli, S.; Schwegler-Berry, D., et al. Unusual inflammatory and fibrogenic pulmonary responses to single-walled carbon nanotubes in mice. Am. J. Phys. Lung Cell. Mol. Physiol. 2005, 289, L698-L708.

[111] Muller, J.; Huaux, F.; Moreau, N.; Misson, P.; Heilier, J. F.; Delos, M.; Arras, M.; Fonseca, A.; Nagy, J. B.; Lison, D. Respiratory toxicity of multi-wall carbon nanotubes. Toxicol. Appl. Pharmacol. 2005, 207, 221-231.

[112] Sayes, C. M.; Liang, F.; Hudson, J. L.; Mendez, J.; Guo, W. H.; Beach, J. M.; Moore, V. C.; Doyle, C. D.; West, J. L.; Billups, W. E., et al. Functionalization density dependence of single-walled carbon nanotubes cytotoxicity In vitro. Toxicol. Lett. 2006, 161, 135-142.

[113] Dong, L.; Joseph, K. L.; Witkowski, C. M.; Craig, M. M. Cytotoxicity of single-walled carbon nanotubes suspended in various surfactants. Nanotechnology 2008, 19, 255702.

[114] Plata, D. L.; Gschwend, P. M.; Reddy, C. M. Industrially synthesized single-walled carbon nanotubes: Compositional data for users, environmental risk assessments, and source apportionment. Nanotechnology 2008, 19, 185706.

[115] Casey, A.; Herzog, E.; Davoren, M.; Lyng, F. M.; Byrne, H. J.; Chambers, G. Spectroscopic analysis confirms the interactions between single walled carbon nanotubes and various dyes commonly used to assess cytotoxicity. Carbon 2007, 45, 1425-1432.

[116] Worle-Knirsch, J. M.; Pulskamp, K.; Krug, H. F. Oops they did it again! Carbon nanotubes hoax scientists in viability assays. Nano Lett. 2006, 6, 1261-1268.

[117] Yang, S. T.; Wang, X.; Jia, G.; Gu, Y.; Wang, T.; Nie, $\mathrm{H}$.; Ge, C.; Wang, H.; Liu, Y. Long-term accumulation and low toxicity of single-walled carbon nanotubes in intravenously exposed mice. Toxicol. Lett. 2008, 181, 182-189.

[118] Yang, S. T.; Fernando, K. A.; Liu, J. H.; Wang, J.; Sun, H. F.; Liu, Y.; Chen, M.; Huang, Y.; Wang, X.; Wang, H., et al. Covalently PEGylated carbon nanotubes with stealth character in vivo. Small 2008, 4, 940-944.

[119] Salvador-Morales, C.; Flahaut, E.; Sim, E.; Sloan, J.; Green, M. L. H.; Sim, R. B. Complement activation and protein adsorption by carbon nanotubes. Mol. Immunol. 2006, 43, 193-201.

[120] Kostarelos, K.; Lacerda, L.; Pastorin, G.; Wu, W.; Wieckowski, S.; Luangsivilay, J.; Godefroy, S.; Pantarotto, D.; Briand, J. P.; Muller, S., et al. Cellular 
uptake of functionalized carbon nanotubes is independent of functional group and cell type. Nat. Nanotech. 2007, 2, 108-113.

[121] Feazell, R. P.; Nakayama-Ratchford, N.; Dai, H.; Lippard, S. J. Soluble single-walled carbon nanotubes as longboat delivery systems for platinum(IV) anticancer drug design. J. Am. Chem. Soc. 2007, 129, 84388349.

[122] Ali-Boucetta, H.; Al-Jamal, K. T.; McCarthy, D.; Prato, M.; Bianco, A.; Kostarelos, K. Multiwalled carbon nanotube-doxorubicin supramolecular complexes for cancer therapeutics. Chem. Commun. 2008, 459-461.

[123] Murakami, T.; Fan, J.; Yudasaka, M.; lijima, S.; Shiba, K. Solubilization of single-wall carbon nanohorns using a PEG-doxorubicin conjugate. Mol. Pharmaceutics 2006, 3, 407-414.

[124] Sun, X.; Liu, Z.; Welsher, K.; Robinson, J. T.; Goodwin, A.; Zaric, S.; Dai, H. Nano-graphene oxide for cellular imaging and drug delivery. Nano Res. 2008, 1, 203212.

[125] Liu, Z.; Robinson, J. T.; Sun, X. M.; Dai, H. J. PEGylated nanographene oxide for delivery of water-insoluble cancer drugs. J. Am. Chem. Soc. 2008, 130, 10876 10877.

[126] Dhar, S.; Liu, Z.; Thomale, J.; Dai, H.; Lippard, S. J. Targeted single-wall carbon nanotube-mediated Pt(IV) prodrug delivery using folate as a homing device. J. Am. Chem. Soc. 2008, 130, 11467-11476.

[127] Liu, Z.; Li, X.; Tabakman, S. M.; Jiang, K.; Fan, S.; Dai, H. Multiplexed multi-color Raman imaging of live cells with isotopically modified single walled carbon nanotubes. J. Am. Chem. Soc. 2008, 130, 13540-13541.

[128] Chakravarty, P.; Marches, R.; Zimmerman, N. S.; Swafford, A. D.; Bajaj, P.; Musselman, I. H.; Pantano, P.; Draper, R. K.; Vitetta, E. S. Thermal ablation of tumor cells with antibody-functionalized single-walled carbon nanotubes. Proc. Natl. Acad. Sci. USA 2008, 105, 8697-8702.

[129] McDevitt, M. R.; Chattopadhyay, D.; Kappel, B. J.; Jaggi, J. S.; Schiffman, S. R.; Antczak, C.; Njardarson, J. T.; Brentjens, R.; Scheinberg, D. A. Tumor targeting with antibody-functionalized, radiolabeled carbon nanotubes. J. Nucl. Med. 2007, 48, 1180-1189.

[130] Kataura, H.; Maniwa, Y.; Kodama, T.; Kikuchi, K.; Hirahara, K.; Suenaga, K.; lijima, S.; Suzuki, S.; Achiba, Y.; Kratschmer, W. High-yield fullerene encapsulation in single-wall carbon nanotubes. Synth. Met. 2001, 121, 1195-1196.

[131] Jeong, G. H.; Farajian, A. A.; Hatakeyama, R.; Hirata, T.; Yaguchi, T.; Tohji, K.; Mizuseki, H.; Kawazoe, Y. Cesium encapsulation in single-walled carbon nanotubes via plasma ion irradiation: Application to junction formation and ab initio investigation. Phys. Rev. B 2003, $68,075410$.

[132] Li, L. J.; Khlobystov, A. N.; Wiltshire, J. G.; Briggs, G. A. D.; Nicholas, R. J. Diameter-selective encapsulation of metallocenes in single-walled carbon nanotubes. Nat. Mater. 2005, 4, 481-485.

[133] Kaneko, T.; Okada, T.; Hatakeyama, R. DNA encapsulation inside carbon nanotubes using micro electrolyte plasmas. Contrib. Plasma Phys. 2007, 47, 57-63.

[134] Hilder, T. A.; Hill, J. M. Modelling the encapsulation of the anticancer drug cisplatin into carbon nanotubes. Nanotechnology 2007, 18, 275704.

[135] Hilder, T. A.; Hill, J. M. Probability of encapsulation of paclitaxel and doxorubicin into carbon nanotubes. Micro Nano Lett. 2008, 3, 41-49.

[136] Mello, C. C.; Conte, D. Revealing the world of RNA interference. Nature 2004, 431, 338-342.

[137] Marshall, E. Clinical trials_-Gene therapy death prompts review of adenovirus vector. Science 1999, 286, 22442245.

[138] Hacein-Bey-Abina, S.; von Kalle, C.; Schmidt, M.; Le Deist, F.; Wulffraat, N.; Mclntyre, E.; Radford, I.; Villeval, J. L.; Fraser, C. C.; Cavazzana-Calvo, M., et al. A serious adverse event after successful gene therapy for $\mathrm{X}$-linked severe combined immunodeficiency. New Engl. J. Med. 2003, 348, 255-256.

[139] Zhang, Z. H.; Yang, X. Y.; Zhang, Y.; Zeng, B.; Wang, Z. J.; Zhu, T. H.; Roden, R. B. S.; Chen, Y. S.; Yang, R. C. Delivery of telomerase reverse transcriptase small interfering RNA in complex with positively charged single-walled carbon nanotubes suppresses tumor growth. Clin. Cancer Res. 2006, 12, 4933-4939.

[140] Choi, H. S.; Liu, W.; Misra, P.; Tanaka, E.; Zimmer, J. P.; Ipe, B. I.; Bawendi, M. G.; Frangioni, J. V. Renal clearance of quantum dots. Nat. Biotech. 2007, 25, 1165-1170.

[141] Wang, H. F.; Wang, J.; Deng, X. Y.; Sun, H. F.; Shi, Z. J.; Gu, Z. N.; Liu, Y. F.; Zhao, Y. L. Biodistribution of carbon single-wall carbon nanotubes in mice. J. Nanosci. 
Nanotech. 2004, 4, 1019-1024.

[142] Deng, X.; Jia, G.; Wang, H.; Sun, H.; Wang, X.; Yang, S.; Wang, T.; Liu, Y. Translocation and fate of multi-walled carbon nanotubes in vivo. Carbon 2007, 45, 14191424.

[143] Pavlinkova, G.; Beresford, G. W.; Booth, B. J. M.; Batra, S. K; Colcher, D. Pharmacokinetics and biodistribution of engineered single-chain antibody constructs of MAb CC49 in colon carcinoma xenografts. J. Nucl. Med. 1999, 40, 1536-1546.

[144] Olmsted, S. S.; Padgett, J. L.; Yudin, A. I.; Whaley, K. J.; Moench, T. R.; Cone, R. A. Diffusion of macromolecules and virus-like particles in human cervical mucus. Biophys. J. 2001, 81, 1930-1937.

[145] Goel, A.; Colcher, D.; Baranowska-Kortylewicz, J.; Augustine, S.; Booth, B. J. M.; Pavlinkova, G.; Batra, S. K. Genetically engineered tetravalent single-chain Fv of the pancarcinoma monoclonal antibody CC49: Improved biodistribution and potential for therapeutic application. Cancer Res. 2000, 60, 6964-6971.

[146] Aubin, J. E. Autofluorescence of viable cultured mammalian cells. J. Histochem. Cytochem. 1979, 27, 36-43.

[147] Wang, F.; Dukovic, G.; Brus, L. E.; Heinz, T. F. Timeresolved fluorescence of carbon nanotubes and its implication for radiative lifetimes. Phys. Rev. Lett. 2004, 92, 177401.

[148] Lefebvre, J.; Austing, D. G.; Bond, J.; Finnie, P. Photoluminescence imaging of suspended single-walled carbon nanotubes. Nano Lett. 2006, 6, 1603-1608.

[149] Reich, S.; Dworzak, M.; Hoffmann, A.; Thomsen, C.; Strano, M. S. Excited-state carrier lifetime in singlewalled carbon nanotubes. Phys. Rev. B 2005, 71, 033402.

[150] Cognet, L.; Tsyboulski, D. A.; Rocha, J. D. R.; Doyle, C. D.; Tour, J. M.; Weisman, R. B. Stepwise quenching of exciton fluorescence in carbon nanotubes by single- molecule reactions. Science 2007, 316, 1465-1468.

[151] Heller, D. A.; Mayrhofer, R. M.; Baik, S.; Grinkova, Y. V.; Usrey, M. L.; Strano, M. S. Concomitant length and diameter separation of single-walled carbon nanotubes. J. Am. Chem. Soc. 2004, 126, 14567-14573.

[152] Crochet, J.; Clemens, M.; Hertel, T. Quantum yield heterogeneities of aqueous single-wall carbon nanotube suspensions. J. Am. Chem. Soc. 2007, 129, 8058-8059.

[153] Keren, S.; Zavaleta, C.; Cheng, Z.; de la Zerda, A.; Gheysens, O.; Gambhir, S. S. Noninvasive molecular imaging of small living subjects using Raman spectroscopy. Proc. Nat. Acad. Sci. USA 2008, 105, 5844-5849.

[154] Zavaleta, C.; Zerda, A. d. I.; Liu, Z.; Keren, S.; Cheng, Z.; Schipper, M.; Chen, X.; Dai, H.; Gambhir, S. S. Noninvasive Raman spectroscopy in living mice for evaluation of tumor targeting with carbon nanotubes. Nano Lett. 2008, 8, 2800-2805.

[155] Xu, M. H.; Wang, L. H. V. Photoacoustic imaging in biomedicine. Rev. Sci. Instrum. 2006, 77, 041101.

[156] Sun, X.; Zaric, S.; Daranciang, D.; Welsher, K.; Lu, Y.; Li, X.; Dai, H. Optical properties of ultrashort semiconducting single-walled carbon nanotube capsules down to sub-10 nm. J. Am. Chem. Soc. 2008, $130,6551-6555$.

[157] Li, X. L.; Tu, X. M.; Zaric, S.; Welsher, K.; Seo, W. S.; Zhao, W.; Dai, H. J. Selective synthesis combined with chemical separation of single-walled carbon nanotubes for chirality selection. J. Am. Chem. Soc. 2007, 129, 15770-15771.

[158] Jorio, A.; Saito, R.; Hafner, J. H.; Lieber, C. M.; Hunter, M.; McClure, T.; Dresselhaus, G.; Dresselhaus, M. S. Structural $(n, m)$ determination of isolated single-wall carbon nanotubes by resonant Raman scattering. Phys. Rev. Lett. 2001, 86, 1118-1121. 